NBER WORKING PAPER SERIES

\title{
CURSE OF ANONYMITY OR TYRANNY OF DISTANCE? THE IMPACTS OF JOB-SEARCH SUPPORT IN URBAN ETHIOPIA
}

\author{
Girum Abebe \\ Stefano Caria \\ Marcel Fafchamps \\ Paolo Falco \\ Simon Franklin \\ Simon Quinn \\ Working Paper 22409 \\ http://www.nber.org/papers/w22409 \\ NATIONAL BUREAU OF ECONOMIC RESEARCH \\ 1050 Massachusetts Avenue \\ Cambridge, MA 02138 \\ July 2016
}

We are grateful to Gharad Bryan, Erica Field, Markus Goldstein, Douglas Gollin, Jeremy Magruder, David McKenzie, Mushfiq Mobarak, Amanda Pallais, and Alemayehu Seyoum Taffesse for helpful comments and to Jali Bekele, Giulio Schinaia, Vaclav Tehle, Biruk Tekle, Marc Witte, Alemayehu Woldu and Ibrahim Worku for outstanding research assistance. Data collection and experimental implementation were funded by GLM | LIC ('Assisting Job Search in Low-Employment Communities: The Effect of Information Provision and Transport Vouchers in Addis Ababa') and by the International Growth Centre ('Assisting Job Search in LowEmployment Communities: The Effect of a Screening Intervention in Addis Ababa'). The project would not have been possible without the constant support of Rose Page and the Centre for the Study of African Economies (University of Oxford), nor without the support of the Ethiopian Development Research Institute in Addis Ababa. This RCT was registered in the American Economic Association Registry for randomized control trials under Trial number AEARCTR-0000911. The views expressed herein are those of the authors and do not necessarily reflect the views of the National Bureau of Economic Research.

At least one co-author has disclosed a financial relationship of potential relevance for this research. Further information is available online at http://www.nber.org/papers/w22409.ack

NBER working papers are circulated for discussion and comment purposes. They have not been peer-reviewed or been subject to the review by the NBER Board of Directors that accompanies official NBER publications.

(C) 2016 by Girum Abebe, Stefano Caria, Marcel Fafchamps, Paolo Falco, Simon Franklin, and Simon Quinn. All rights reserved. Short sections of text, not to exceed two paragraphs, may be quoted without explicit permission provided that full credit, including (C) notice, is given to the source. 
Curse of Anonymity or Tyranny of Distance? The Impacts of Job-Search Support in Urban

Ethiopia

Girum Abebe, Stefano Caria, Marcel Fafchamps, Paolo Falco, Simon Franklin, and Simon

Quinn

NBER Working Paper No. 22409

July 2016

JEL No. J64,015,O18

\section{ABSTRACT}

We conduct a randomized evaluation of two job-search support programs for urban youth in Ethiopia. One group of treated respondents receives a subsidy to cover the transport costs of job search. Another group participates in a job application workshop where their skills are certified and they are given orientation on how to make effective job applications. The two interventions are designed to lower spatial and informational barriers to employment. We find that both treatments significantly improve the quality of jobs that young jobseekers obtain. Impacts are concentrated among women and the least educated. Using rich high-frequency data from a phone survey, we are able to explore the mechanisms underlying the results; we show that while the transport subsidy increases both the intensity and the efficacy of job search, the job application workshop mainly operates through an increase in search efficacy. Both interventions mitigate the adverse effects of spatial constraints on employment outcomes, and the job application workshop alleviates informational asymmetries by helping workers to signal their ability.

Girum Abebe

EDRI

Addis Ababa

Ethiopia

girumpop@yahoo.com

Stefano Caria

Oxford Department of International Development

Oxford University

Oxford UK

stefano.caria@qeh.ox.ac.uk

Marcel Fafchamps

Freeman Spogli Institute

Stanford University

616 Serra Street

Stanford, CA 94305

and NBER

fafchamp@stanford.edu
Paolo Falco

OECD

Paris

France

paolo.falco@oecd.org

Simon Franklin

Centre for Economic Performance

London School of Economics

S.Franklin1@1se.ac.uk

Simon Quinn

Oxford University

simon.quinn@economics.ox.ac.uk

A randomized controlled trials registry entry is available at https://www.socialscienceregistry.org/trials/911 


\section{Introduction}

Over half of the world's population lives in a city and global urbanisation is proceeding at a rapid pace, especially in developing countries. By 2050, the urban population of Africa is expected to triple, while that of Asia is expected to grow by 61 percent (United Nations, 2014). A key challenge for policy makers is to find ways to support a growing urban labour force, and in particular those workers who find it hardest to access the opportunities that cities have to offer. These individuals tend to be young and are predominantly female. They have left school after completing compulsory education, they have little work experience, and they live in poorly connected parts of the city. A growing literature argues that their labor market opportunities are reduced by the cost of job search and their inability to signal skills during the recruitment process (Card et al., 2007; Chetty, 2008; Crépon et al., 2013; Pallais, 2014). Limited labour market opportunities can reduce well-being, depreciate human capital, and change preferences (Clark and Oswald, 1994; Fisman et al., 2015). Search frictions also affect competition between firms and distort the allocation of labour (Kaas and Kircher, 2015; Bryan and Morten, 2015). Yet, despite the importance of these effects, we have surprisingly little evidence documenting how job search constraints can be addressed in the growing cities of developing economies.

In this paper, we experimentally evaluate two interventions that are designed to help young urban dwellers search for employment. The first intervention is a transport subsidy. Job search in our study area requires regular trips to the centre of town and we calibrate the subsidy amount to cover the cost of this journey. Individuals who are offered this program can collect the subsidy from an office located in the centre of the city, up to three times a week, for an average period of 16 weeks. The second intervention is a job application workshop. Participants are offered orientation on how to make effective job applications using CVs and cover letters and on how to approach job interviews. Further, during the event, participants take a mix of standardised personnel selection tests. We use information from the tests to certify participants' general skills. These two interventions are designed to ease spatial and informational constraints to job search. We hypothesised that treated jobseekers would search more intensely and more effectively, leading to improved 
employment outcomes.

We evaluate these interventions using a random sample of about 4,000 young individuals in a rapidly expanding metropolis located in a fast growing country - namely, Addis Ababa, the capital of Ethiopia. This location is ideal for our purpose: a large city with a total population close to 4 million people, unemployment rates above 20 percent, many insecure and poorly paid jobs, and rapid in-migration from outlying rural areas. Because of our interest in search costs related to transport, we focus on subjects who reside at least $2.5 \mathrm{~km}$ away from the centre of town. ${ }^{1}$

We find that both interventions help jobseekers get better jobs. Eight months after the end of the program, individuals invited to the job application workshop are nearly 40 percent more likely to have permanent employment and nearly 25 percent more likely to be in formal employment compared to individuals in the control group. Individuals who are offered the transport subsidy are 25 percent more likely to be in formal employment. These effects are statistically significant; they are robust to a correction for multiple comparisons; and their magnitude is economically meaningful. The effects are stronger for women and for less educated workers (those who have at most secondary education). These are the groups that typically find it hardest to obtain high quality employment, in Ethiopia and in other developing countries (OECD, 2015).

To understand the mechanisms that drive these results, we conduct fortnightly phone interviews with all sampled jobseekers throughout the course of the study. This provides a rich, high-frequency dataset that allows us to observe how search behaviour evolves in response to our interventions. ${ }^{2}$ We find that the transport subsidy allows jobseekers to search more intensely. Furthermore, we find that both interventions improve jobseekers' search efficacy, particularly for the least educated. On average, control individuals with a high school degree receive an offer for a permanent job every 10.5 applications. The workshop and the transport programs bring this down to about one offer every 5.2 applications.

\footnotetext{
${ }^{1}$ Individuals included in the study are between 18 and 29 years of age, have completed high school, are available to take up employment, and are not currently working in a permanent job.

2 Recall bias would make it difficult to perform a similar analysis using retrospective questions asked in the endline survey.
} 
We also present evidence consistent with the hypothesis that the interventions work by easing spatial and informational constraints. In particular, both interventions weaken the correlation between distance from the city centre and the type of occupation that participants undertake. Furthermore, using data from the personnel selection tests, we find that the job application workshop strengthens the correlation between skills and good employment outcomes for workers with less formal qualifications. We present evidence from a regression discontinuity analysis suggesting that this effect is mostly driven by the orientation component of the job application workshop.

Finally, we measure the indirect impacts of the interventions on the young individuals who reside close to program participants. Using a randomised saturation design, we find some positive indirect effects of the transport subsidy on the quality of employment when the proportion of treated jobseekers is low, and some negative effects when the proportion of treated jobseekers is high $(90 \%)$. We do not find indirect effects of the job application workshop, despite a fairly high proportion of treated respondents in all clusters $(80 \%)$.

Taken together, our evidence shows that the urban unemployed can benefit from simple interventions that facilitate job search, at least in the context of least developed countries where the problem is particularly acute. Recent studies have documented that search subsidies and information can connect rural workers to urban jobs (Jensen, 2012; Bryan et al., 2014). We show that job search assistance can also be effective for workers in urban labour markets.

There is little experimental evidence documenting the impacts of transportation subsidies and jobseekers' orientation interventions. Using a randomized field experiment in Washington DC, Phillips (2014) finds that a public transit subsidy has a large, short-run effect in reducing unemployment durations, with treatment causing the probability of finding employment within 40 days to increase by 9 percentage points, from 0.26 to 0.35 . After 90 days, this difference narrows to a large but statistically insignificant 5 percentage points. For less developed countries, Franklin (2015) reports the results of an early trial of a transport subsidy intervention administered to a selected sample of motivated jobseekers in Addis Ababa. He also finds positive impacts on the probability of permanent work. Groh 
et al. $(2015,2016)$ find that a soft skills training program and a matching intervention do not improve the employment outcomes of young Jordanian women. These two interventions have a number of features in common with the job application workshop - chiefly, the focus on information about skills. However, they are offered to a sample of jobseekers with tertiary education, in a labour market with much higher unemployment rates. In line with their results, we are unable to find significant treatment effects for individuals with tertiary education, but we find that this type of intervention can benefit less educated workers.

More generally, our results contribute to our understanding of how space affects the functioning of labour markets (Gollin and Rogerson, 2010; Bryan and Morten, 2015; Asher and Novosad, 2015). We sample young individuals who reside in many different parts of Addis Ababa and we record detailed geo-coded information about their place of residence. This allows us to document the spatial pattern of occupational structure in the city and to calculate heterogeneous treatment effects by distance from the city centre. We find that both our interventions help jobseekers overcome the spatial constraints on occupational choices.

We also contribute to a growing literature that studies the economic importance of cognitive and non-cognitive skills (Bowles et al., 2001; Heckman et al., 2006; Blattman et al., 2015). We draw from this literature to develop the personnel selections tests used in the study. Our evidence suggests that in some segments of the labour market employers may be unable to identify highly skilled workers. The job application workshop overcomes this. Our results relate directly to the findings in Pallais (2014), who documents the positive employment effects of an interventions that helps workers signal their skills in an online labour market.

Finally, we provide the first evidence on the local indirect effects of labour market interventions in a developing country. Using a randomised saturation design as in Crépon et al. (2013), we show that indirect effects on non-participants depend on the proportion of jobseekers that are offered the program in a given area.

The rest of the paper is organised as follows. Section 2 provides some information 
about the labour market in Addis Ababa. Section 3 describes the two interventions. In section 4 , we introduce the experimental design, the data we use, and the main empirical specification. Section 4 presents the main results. In section 5, we discuss the nature of the constraints addressed by our interventions. We conclude with some thoughts about future interventions.

\section{Context}

Addis Ababa is the largest city in Ethiopia (African Economist, 2012). Official estimates suggest that the population of the city totalled 3.2 millions in 2014 and planners expect that Addis Ababa's population will more than double in the next 25 years (CSA, 2014; Davison, 2014). ${ }^{3}$ Many of the city residents are unemployed. The overall unemployment rate is 23.5 percent. ${ }^{4}$ Young people between the age of 20 and 29 face an unemployment rate of 27.9 percent, and young women a rate of 33.6 percent (CSA, 2014). Furthermore, available jobs are often insecure and poorly paid. At the time of the endline survey of our study, only 30 percent of the employed individuals in the control group have a permanent job. The others work in temporary, casual or self-employment. The stream of income from these occupations is unstable. For example, 25 percent of temporary workers report that they had to miss at least one week of work, since they started their current job, because "work was not available". ${ }^{5}$ Working poverty is widespread: two workers out of five earn less than 2 USD per day. ${ }^{6}$

Job search is costly for unemployed youth. One of the most popular search methods

\footnotetext{
${ }^{3}$ Other estimates suggest that the total population of the city is close to 4.5 million.

4 To calculate this rate, the Central Statistical Authority of Ethiopia counts as unemployed all individuals who do not have a job, but are available for work.

5 The median duration of these spells was 4 weeks for temporary workers and 8 weeks for the self-employed.

${ }^{6}$ Median earnings in the control group at endline are about 70 USD per month. If we adjust this figure using the World Bank purchasing power parity conversion rates, this corresponds to about 205 USD. However, Addis Ababa is the most expensive city in Ethiopia. Thus when we use the nation-wide PPP adjustment factor we overestimate the real purchasing power of salaries in the capital city. Data from the Ethiopian Statistical Authority documents that in 20142 employed individuals out of 5 in Addis Ababa were available to work additional hours, further suggesting underemployment and low pay.
} 
used by the participants in our study is to visit the job vacancy boards. ${ }^{7}$ The boards are located in the centre of the city, forcing participants who live in the periphery to travel frequently to the centre of the city, which can be costly. Job seekers also face the costs of gathering information through newspapers, printing CVs and cover letters, travelling to interviews, etc. Among the active searchers in our sample, the median expenditure on job search at baseline amounts to about 16 percent of overall expenditure. This goes up to 25 percent for jobseekers who report searching 6 days a week. These are large amounts especially if we consider that the typical jobseeker spends a long time in unemployment before finding a job. In our baseline sample, for example, the median jobseekers has spent about 10 months looking for employment.

Young jobseekers in Addis Ababa find it hard to signal their skills and worth to employers. To select a shortlist of candidates among a large number of applicants, firms in the city often use simple criteria such as whether the candidate has previous work experience. ${ }^{8}$ Job referrals are also frequent (Serneels, 2007; Caria, 2015). This puts young people at a disadvantage, as they have little work experience and less extensive networks. 55 percent of the participants in our study report having less than one year of work experience and only 16 percent have ever worked in a permanent job. Furthermore, many jobseekers do not seem to be familiar with the process and the standards of job applications. For example, while firms report valuing a well-written $C V, 41$ percent of the study participants who have applied for at least one job in the last six months have not prepared a CV to support their applications.

In light of these challenges, we devised three interventions to support young unemployed workers in their job-search. This paper focuses on the first two treatments. The third one, which is briefly described in Section 2.4, will be the focus of a separate paper.

\footnotetext{
${ }^{7}$ At baseline, 36 percent of participants rank the job vacancy boards as their preferred method of search and 53 percent of active searchers have visited the boards at least once in the previous seven days.

856 percent of firms report that for blue collar positions they only consider candidates with sufficient work experience, and 63 percent of firms use this selection method for white collar positions.
} 


\section{The interventions}

\subsection{Treatment 1: The transport subsidy}

Individuals in this treatment group are offered cash conditional on attending an office in the centre of Addis Ababa. ${ }^{9}$ Recipients are required to attend in person, and to show photographic ID on each visit. Each recipient can collect cash once a day, up to three times a week. The amount that can be collected on any given day is calibrated to cover the cost of a return bus fare from the area of residence of the participant at baseline to the intervention office. ${ }^{10}$

The median subsidy available on a given day is equal to 20 Ethiopian Birr (1 USD at the exchange rate at the beginning of the intervention). This is about two thirds of the median weekly expenditure on job search at baseline, and 10 percent of overall weekly expenditure. The minimum amount is 15 ETB (0.75 USD) and the maximum 30 ETB (1.5 USD).

We stagger the start time and the end time of the subsidy, randomly. This generates variation across individuals in the number of weeks during which the treatment was available, and in the time of treatment. The number of weeks of treatment varied from 13 to 20 , with a median of 16 weeks. We implement the intervention between September 2014 and January 2015.

\subsection{Treatment 2: The job application workshop}

The job application workshop is designed to help jobseekers signal their skills to employers. It has two components: an orientation session and a testing session. The orientation session helps jobseekers make more effective use of their existing signals (job experience, educa-

${ }^{9}$ This office is located close to the major job vacancy boards. The office was also near a central bus station, from which buses leave to destinations all around Addis Ababa.

${ }^{10}$ We calibrate the subsidy to allow participants to travel on minibuses. Study participants can in principle walk to the office or use less expensive large public buses - an inferior means of transport that is crowded and infrequent - and save a part of the transfer. Qualitative evidence suggests that this is not common. Furthermore, we do not find that individuals in this treatment group increase their savings during the weeks of the intervention. 
tion, etc.). In the testing session, we certify skills that are "hard to observe" for employers, such as cognitive ability, and we provide participants with an instrument (the certificates) to signal those skills.

The intervention takes place over two days. On the first day, participants take the tests. On the second day, they attend the orientation session. The intervention is administered by the School of Commerce of Addis Ababa University, between September and October 2014. The School of Commerce has a reputation for reliable personnel selection services and many firms screen their applicants using tests developed, and sometimes administered by, the School of Commerce. In a survey of 500 medium to large firms in Addis Ababa, we find that about 40 percent of firms know about the personnel selection services offered by the School of Commerce (Abebe et al., 2015). 80 percent of these firms report that they trust the services offered by the School of Commerce.

The orientation session covers three main topics: CV writing, application letters and job interviews. All the training materials were developed by the School of Commerce and later reviewed by our team. We administer four tests: (i) a Raven matrices test, (ii) a test of linguistic ability in Amharic, (iii) a test of mathematical ability and (iv) a 'worksample' test. The results of the tests are presented in a certificate, which jobseekers can use in support of their job applications. The certificates explain the nature of the tests and report the relative grade of the individual for each test, and an aggregate measure of performance. ${ }^{11}$ The certificates are officially issued by the School of Commerce and the Ethiopian Development Research Institute. ${ }^{12}$

We chose the tests on the basis of the results of several qualitative interviews with firm managers in the city. ${ }^{13}$ The Raven test is a widely used measure of cognitive ability (Raven, 2000). It is believed to be one of the best predictors of worker productivity (Schmidt and Hunter, 1998; Chamorro-Premuzic and Furnham, 2010) and it has been used by economists

\footnotetext{
11 We report relative performance using bands: a band for the bottom 50 percent of the distribution and then separate bands for individuals in the upper deciles of the distribution: $50-60 \%, 60-70 \%, 70-80 \%, 80-90 \%$, $90-100 \%$.

12 Participants collect the final certificates from the School of Commerce, after all testing sessions are completed.

13 These interviews highlights managers' information needs and the degree of familiarity that managers have with various tests.
} 
to measure worker quality in several contexts (Dal Bó et al., 2013; Beaman et al., 2013). The tests of mathematical and linguistic ability are designed to capture general mathematical and linguistic skills, as in the OECD's PIAAC survey or the World Bank's STEP survey (OECD, 2013; Pierre et al., 2014). The 'work-sample' test captures participants' ability to carry out simple work tasks: taking minutes during a business meeting, carrying out a data entry task under time pressure, and meeting a deadline to complete a data entry task at home. The literature in organisational psychology suggests that 'work-sample' tests can be used alongside measures of cognitive ability to predict worker performance (Schmidt and Hunter, 1998).

\subsection{Job fair}

Alongside the two treatments that we study in the paper, we also implemented a third intervention. Individuals assigned to this treatment, were invited to attend, free of charge a job fair. This is a distinct treatment, which we plan to evaluate in a separate paper.

\section{Experimental design and data}

\subsection{The sample}

We randomise treatment assignment at two levels: geographic clusters and individuals. We defined geographic clusters using the Ethiopian Central Statistical Agency (CSA) enumeration areas. ${ }^{14}$ Our sampling frame excluded clusters within $2.5 \mathrm{~km}$ of the centre of Addis Ababa, and clusters outside the city boundaries. Clusters were selected at random from our sampling frame, with the condition that directly adjacent clusters could not be selected, to minimise potential spill-over effects across clusters.

In each selected cluster, we used door-to-door sampling to construct a list of all individuals in the cluster who: (i) were 18 or older, but younger than 30; (ii) had completed

\footnotetext{
14 CSA defines enumeration areas as small, non-overlapping geographical areas. In urban areas, these typically
} consist of 150 to 200 housing units. 
high school; (iii) were available to start working in the next three months; and (iv) were not currently working in a permanent job or enrolled in full time education. We randomly sampled individuals from this list to be included in the study. Our lists included individuals with different levels of education. We sampled with higher frequency from the groups with higher education. This ensured that individuals with vocational training and university degrees are well represented in the study. All selected individuals were contacted for an interview.

We completed baseline interviews with 4388 eligible respondents. We attempted to contact individuals by phone for at least a month (three months, on average); we dropped individuals who could not be reached after at least three attempted calls. ${ }^{15}$ We also dropped any individual who had found a permanent job and who retained the job for at least six weeks. Finally, we dropped individuals who had migrated away from Addis Ababa during the phone survey. Table 8 in the online appendix shows of how many individuals were dropped from the sample at each point and the reasons for them being dropped. In all we were left with 4059 individuals who were are included in our experimental study.

\subsection{Face-to-face interviews and the phone survey}

We collect data on study participants through both face-to-face and phone interviews. We complete baseline face-to-face interviews between May and July 2014 and endline interviews between June and August 2015. We collect information about the sociodemographic characteristics of study participants, their education, work history, finances and their expectations and attitudes. We also include a module to study social networks.

We also construct a rich, high-frequency panel dataset through fortnightly phone interviews. We call all study participants through the duration of the study. In these interviews we administer a short questionnaire focused on job search and employment. Franklin (2015) shows that high-frequency phone surveys of this type do not generate Hawthorne

\footnotetext{
15 We give details of the phone interviews in section 4.2 below
} 
effects, for example, they do not affect jobseekers' responses during the endline interview.

\subsection{Randomisation}

We randomly assigned geographic clusters to one of five treatment groups: (i) control, (ii) transport, (iii) job application workshop, (iv) job fair, (v) job fair and workshop. To ensure balance, we created blocks of clusters with similar baseline observables and randomly assigned clusters within each block to the five groups (Bruhn and McKenzie, 2009). ${ }^{16}$

Not all individuals in the clusters assigned to the transport intervention and job application workshop were designated to receive treatment. Among those in the transport clusters, we implemented a randomised saturation design. We varied the proportion of sampled individuals who were offered treatment from $20 \%$ to $40 \%, 75 \%$ and $90 \%$. Table 2 shows the number of clusters assigned to each saturation level and the number of individuals who were offered treatment in those clusters.

In clusters assigned to the job application workshop we kept the level of saturation fixed. $80 \%$ of all individuals in these clusters were invited to attend the workshop. Having set cluster saturation levels, we assigned individuals within clusters to treatment and controls. This was done by blocking individuals within clusters by their education level, and implementing a simple re-randomisation rule. The final assignment to treatment is outlined in Table 1. Finally, individuals designated to receive the transport intervention were randomly assigned to a start and an end week. This is illustrated in table 9 in the online appendix.

\section{< Table 1 here. $>$}

$<$ Table 2 here. $>$

\footnotetext{
${ }^{16}$ We used the following variables to create the blocks: distance of cluster centroid from city centre; total sample size surveyed in the cluster; total number of individuals with degrees; total number of individuals with vocational qualifications; total number of individuals who have worked in the last 7 days; total number of individuals who have searched for work in the last 7 days; total number of individuals of Oromo ethnicity; average age of individuals in the cluster.
} 


\subsection{Balance and Attrition}

We find that our sample is balanced across all treatment and control groups, and across a wide range of outcomes. This includes outcomes that were not used in the randomisation procedure. We present extensive balance tests in Table 10 in the online appendix. For each baseline outcome of interest, we report the p-values for a test of the null hypothesis that all experimental groups are balanced. We cannot reject this null for any of variables that we study.

Attrition in our sample is low, especially compared to other studies of young adults in Sub-Saharan Africa (Baird et al., 2011; Blattman et al., 2013). In the endline survey, we find $93.5 \%$ of all participants. The probability of tracking original study participants is very similar across experiment groups. We cannot reject the null hypothesis that there are no differences in attrition rates between treatment and control individuals when we study each treatment individually, or when we run a joint test for all treatments. A number of covariates predict attrition. Since neither these variables, nor attrition, are correlated with treatment, we are not worried that this is affecting our results. Table 11 in the online appendix presents the analysis of attrition.

Attrition in the phone survey is also low, below 5\% in the early months of the calls. We find that while attrition increases in the later week of the study, we are still able to contact more than $90 \%$ of respondents in the final month of the phone survey. Figure 19 in the online appendix shows the trajectory of monthly attrition rates over the course of the phone survey. ${ }^{17}$

\subsection{Take-up}

$50 \%$ of individuals in the transport group collect the cash at least once. Of these, $19 \%$ do not return to collect the subsidies again. Those who collected the subsidies for at least

\footnotetext{
17 We do not report attrition rates at the very beginning of the phone survey since many respondents were only contacted for the first time in months 2 and 3 of the phone survey, either because they were surveyed towards the end of the baseline survey, and because of lags in setting up the phone survey.
} 
two weeks tended to be dedicated users. Conditional on coming to take up the money at least, $74 \%$ of respondents took up the money at least once a week over the course of the entire study. The average number of total collections among those who took it up was 16, corresponding to an average cash transfer of 320 ETB (15 USD) per active user, or 160 ETB (7.5 USD) per intended user.

$63 \%$ of individuals in the job application workshop group attended the workshop. $80 \%$ of those attending later collected the certificates from the School of Commerce. Not all of these jobseekers chose to use the certificates to support their job applications. Among the study participants who collected the certificates and applied to at least one position, 42 percent report ever including the certificates in an application. ${ }^{18}$ When they did so, participants report that the firms took the information into consideration.

\section{$5 \quad$ Empirical strategy}

We follow a detailed pre-analysis plan registered at: www.socialscienceregistry.org/ trials/911. The plan describes the empirical strategy, the outcome variables of interest, the definition of these variables, the subgroup analysis, and our approach to multi-hypothesis testing and attrition.

Our primary objective is to estimate the effects of the programs on the labour market outcomes of study participants. For each outcome at endline, we will estimate the following equation:

$$
\begin{aligned}
y_{i c}= & \beta_{0}+\beta_{1} \cdot \text { transport }_{i}+\beta_{2} \cdot \text { workshop }_{i}+\beta_{3} \cdot \text { jobfair }_{i} \\
& +\gamma_{1} \cdot \text { spillover }_{i}+\gamma_{2} \cdot \text { spillover }_{i}+\alpha \cdot y_{i c, p r e}+\boldsymbol{\delta} \cdot \boldsymbol{x}_{i 0}+\mu_{i c}
\end{aligned}
$$

where $y_{i c}$ is the endline outcome for individual $i$ in cluster $c$ and $\boldsymbol{x}_{i 0}$ is the vector of baseline covariate values that were used for re-randomisation and blocking. transport ${ }_{i}$

\footnotetext{
18 This is unlikely to be caused by poor understanding, as participants report to have understood the informa-
} tion presented in the certificates well and certificates use is correlated with the score reported. 
workshop $_{i}$, jobfair $i$ are dummies that capture whether an individual has been offered a particular program. ${ }^{19}$ Thus, our estimates measure the intent-to-treat impacts of the interventions. In this paper we focus on the effects of the transport and job application workshop. As discussed, the effects of the job fair intervention will be reported in a separate paper. spillover $1_{i}$ identifies control individuals residing in clusters assigned to the transport treatment, while spillover $2_{i}$ identifies control individuals in clusters assigned to the job application workshop. We correct standard errors to allow for correlation within geographical clusters. As we explained above, we sampled individuals who have attained high education levels with higher frequency. To obtain average treatment effects for the population of eligible individuals, we weight observations according to the inverse of the probability of being sampled. ${ }^{20}$

In the pre-analysis plan, we specify a family of seven primary employment outcomes. For each one of them we we test the null hypothesis that each treatment had no impact. We report both a conventional p-value and a 'sharpened' q-value (Benjamini et al., 2006). The q-values control the false discovery rate within the family of the seven hypotheses that we test for each program. We also specify two families of intermediate outcomes that help us elucidate what mechanisms drive the primary effects, and seven families of secondary outcomes. To deal with secondary outcomes, we will use a standard 'omnibus' approach: we construct an index for each family and test whether the index is affected by our treatments. For inference, we proceed as before: we report both $\mathrm{p}$ values and false discovery rate q-values by treating each index as a separate member of a 'super-family' of indices.

\footnotetext{
${ }^{19}$ We administered two different versions of the job fairs treatment. We follow the pre-analysis plan and include a separate dummy for each version of the job fair treatment. For simplicity of exposition, in equation 1 we collapse the two dummies into one. Since the effects of the job fairs will be the focus of a separate paper, they will not be reported below.

20 We use the sampling weights reported in the pre-analysis plan.
} 


\section{Results}

We first present the impacts of each program on the primary employment outcomes. Table 3 summarises the results. Each row in the table corresponds to an outcome variable. We study impacts on overall employment rates, on the number of hours worked and on the probability of having a permanent job and a job with a written agreement. In Ethiopia, workers are often employed without a written agreement, which makes it difficult for them to uphold their formal rights and for the fiscal authority to collect labour taxes. ${ }^{21}$ Thus, having a written agreement represents a salient measure of employment formality. We also test for effects on the probability of being self employed, on earnings and work satisfaction. The first two columns of table 3 report impacts on treated individuals. Columns 3 and 4 show impacts on control individuals in treated clusters (the indirect effects of the programs). Below each coefficient we report a p-value in parentheses and a q-value in brackets. The mean outcome for the control group at endline is shown in column 5 . In column 6 we report the results of an F-test for the equality of the effects of the two interventions.

\section{< Table 3 here. $>$}

We find that both interventions significantly improve the quality of the jobs workers get. The application workshop increases the probability of working in a permanent job by nearly 40 percent (raising the share of workers in permanent employment by 6.7 percentage points from a level of 17.1 percent in the control group). The effect is statistically significant at the 1 percent level and remains highly significant after correcting for multiple comparisons. The transport treatment boosts permanent employment by nearly 20 percent (a 3.4 percentage points increase from the control level). This effect is significant at the 10 percent level, but has a q-value of 0.23 once we account for multiple comparisons. Both

${ }^{21}$ In the endline survey of our study, only 44 percent of workers have signed a written agreement with their employer. Those who do are 60 percent less likely to report delays in wage payments and 22 percent more likely to have received information about health and safety regulations. Furthermore, workers with a written agreement are less likely to be working in small shops, construction sites and open markets (locations that are prone to informality), and more likely to be working in an office or a factory. 
effects are also robust to the use of Lee bounds to correct for attrition. ${ }^{22}$ We report these bounds in table 25 of the online appendix.

We also find that both interventions increases workers' chances to have a formal job (proxied by a written contract) by nearly 25 percent. Only 22 percent of the control group has a formal job at endline and both programmes increase that figure by 5 percentage points. The effects are robust to the multiple comparison correction and to the use of Lee bounds to correct for attrition.

The interventions have modest and insignificant effects on the overall employment rate of treated individuals. About 56 percent of controls are engaged in some form of work at endline. This goes up by an insignificant 4 percentage points for individuals in the transport treatment, and by an insignificant 2 percentage points for individuals who were invited to the job-application workshop. The types of occupations that workers are engaged in are also similar across treatment and control individuals. In figures 1 and 2 we give a breakdown of the ten most common occupations in the three experimental groups.

Earnings and work satisfaction are similar across experimental groups. This is in line with the findings of a number of recent experimental studies of labour market interventions in developing countries (Groh et al., 2012; Jensen, 2012; Franklin, 2015). Further, the coefficients we estimate are consistent with the magnitude of the effects on the quality of jobs outlined above. We cannot reject the hypothesis that the treatment impacts on these two variables do not differ from the naive prediction obtained from multiplying the treatment impacts on permanent and formal work by their marginal effects on earnings and work-satisfaction. For example, among the controls, permanent work is associated with a 25 percentage points increase in work satisfaction, and formal work with a 22 percentage point increase. Individuals invited to the workshop are 6.7 percentage points more likely to have permanent work, and 5.2 percentage points more likely to have formal work. Multiplying the two effects and adding up, we predict that work satisfaction should increase by 2.7 percentage points in the job search support group. The estimated treatment effect on work satisfaction for this experimental group is 2.1 percentage points, quantitatively close

\footnotetext{
22 This is not surprising, as attrition in this study is modest and is not significantly correlated with treatment.
} 
and statistically indistinguishable from the naive prediction.

In addition to testing the effects of the interventions on the primary employment outcomes, we evaluate their impacts on a range of secondary outcomes, including (i) other outcomes about job quality, (ii) financial outcomes, (iii) expectations, reservation wages and aspirations, (iv) spatial mobility, (v) education and training, (vi) psychological outcomes and (vii) social and job networks (the details are available in tables 17 to 24 in the online appendix). Overall we find little evidence that our interventions have changed outcomes in any of these areas. We have some limited evidence that the jobseekers who were invited to the job application workshop are more optimistic about their labour market prospects. They expect to receive 20 percent more job offers in the next four months than individuals in the control group. They also expect five weeks less of unemployment before finding the next job. Only the first effect is significant, and does not survive the multiple comparison correction.

\subsection{Which groups benefit from the interventions?}

We investigate treatment effects for a number of groups defined in the pre-analysis plan. We are interested in heterogeneity along two key dimensions. First, do the interventions help groups that typically have worse labour market outcomes - for example, women or the less educated? Second, do the interventions help those who face the strongest job search constraints? To identify constrained jobseekers, we first look at individuals who spent less than the median number of weeks searching for a job in the three months prior to the randomisation. We then investigate proxies for financial, spatial and informational constraints. In particular, we use baseline measures of savings, distance from the city centre, previous work experience, and the use of skills certificates or a CV. When such characteristics are continuous, we create groups by separating individuals below and above 
the median level of the characteristic. For each outcome, we run the following specification:

$$
\begin{aligned}
y_{i c}= & \sum_{v=0}^{m}\left[\beta_{v}+\sum_{f=1}^{4} \gamma_{v f} \cdot \operatorname{treat}_{f i} \cdot I\left(x_{i, p r e}=v\right)+\gamma_{v 5} \cdot \operatorname{spillover}_{1 i} \cdot I\left(x_{i, p r e}=v\right)\right. \\
& \left.+\gamma_{v 6} \cdot \operatorname{spillover}_{2 i} \cdot I\left(x_{i, p r e}=v\right)\right]+\alpha \cdot y_{i c, p r e}+\boldsymbol{\delta} \cdot \boldsymbol{x}_{i 0}+\mu_{i c},
\end{aligned}
$$

where $x_{i, p r e}$ is a categorical variable with values $\{0, \ldots, m\}$, and $I\left(x_{i, p r e}=v\right)$ is a indicator variable that takes the value of 1 when $x_{i, p r e}$ is equal to $v$. The coefficients $\gamma_{v f}$ estimate the effect of treatment $f$ for group $v$.

$<$ Figure 3 here. $>$

$<$ Figure 4 here. $>$

$<$ Figure 5 here. $>$

$<$ Figure 6 here. $>$

We find that the effects on job quality (permanent and formal work) are concentrated among the least educated jobseekers and, to some extent, among women. To study heterogeneity by education, we separate individuals who have a high school degree and no further education, individuals who have a high school degree and further vocational training, and individuals who have a university degree or above. Figures 3 and 4 show that the effects of both interventions are mostly driven by the group that has only a high school degree. For this group, the job application workshop raises the probability of permanent employment by 10 percentage points, and the transport intervention raises it by 5 percentage points. On the other hand, treatment effects for individuals with higher educational attainment are close to zero. In the control group, about 5 percent of individuals with at most secondary education have a permanent job. The workshop, therefore, triples the probability of permanent employment for this group, and the transport subsidy doubles 
it. We find qualitatively similar results for the formality of employment. Impacts are concentrated among individuals with a high school degree, who experience an increase in the probability of formal employment of about one third.

Both the transport intervention and the workshop significantly improve the the quality of jobs for women. We report these results in figure 5, and table 5 in the appendix. The transport intervention significantly increases both women's probability of permanent work and probability of formal work by 35 percent, while women invited to the workshop are about 45 percent more likely to work in a permanent job, and 35 percent more likely to be in formal employment. Effects for men are less robust. The transport intervention does not increase the probability of permanent employment for men. We can reject the null hypothesis that the effect of the transport intervention on permanent work is equal for men and women at the 5 percent level. Further, the job application workshop has a small and insignificant impact on men's probability of being in formal employment, and effect that is statistically different from the effect we measure for women.

Second, the improvement in job quality is concentrated among individuals who do not search actively at baseline, individuals with no previous work experience, and individuals with low savings (tables 13, 14 and 15 in the online appendix). For example, individuals who do not search actively at baseline experience a significant increase in the likelihood of permanent employment of about 9 percentage points when invited to the job application workshop. For active jobseekers on the other hand, we estimate an insignificant increase of 4 percentage points.

When we investigate how treatment effects vary with distance from the centre, we obtain a nuanced picture. The permanent employment effects are driven by individuals who live within $6 \mathrm{~km}$ of the city centre. Treatment effects are smaller in magnitude and insignificant for individuals who live in the periphery. However, individuals living in the periphery experience a significant and marked decline in the probability of self employment thanks to the transport intervention. This effect is not observed for individuals living closer to the centre and for individuals invited to the job application workshop. In the final section of the paper we discuss this finding in greater deal. 


\subsection{Mechanisms}

How do treated individuals obtain jobs of higher quality? We study three possible mechanisms. First, individuals who are offered the interventions can search more intensely, for example they can dedicate more time to job search and they can make more applications. Second, treated individuals can change their search strategy. This can either involve searching for different jobs or using different search methods. Finally, treated jobseekers can become more effective at job search. We measure search effectiveness by computing the ratio of job interviews to applications and the ratio of job offers to applications in the 12 months prior to the endline interview.

In this section, we make extensive use of the high frequency data from the phone interviews. Pooling data from the phone calls across all weeks enables us to estimate the weekly impact of the interventions and the overall trajectory of treatment effects. We estimate two regression models. First, to obtain weekly impact estimates, we run:

$$
\begin{aligned}
y_{i t c}= & \eta_{t}+\sum_{g=1}^{4} \sum_{w=S_{g}}^{E_{g}} \beta_{g w} \cdot \text { treat }_{g i} \cdot d_{w i t} \\
& +\sum_{s=1}^{2} \sum_{w=S_{s}}^{E_{s}} \gamma_{s w} \cdot \text { spillover }_{s i} \cdot d_{w i t}+\alpha_{t} \cdot y_{i t c, p r e}+\boldsymbol{\delta} \cdot \boldsymbol{x}_{i 0}+\mu_{i t c} .
\end{aligned}
$$

where $\eta_{t}$ is a time-specific intercept term. We allow the effect of the baseline control term $y_{i c, p r e}$ to vary over time by estimating $\alpha_{t}$ for each time period, while we estimate time-invariant effects of individual covariates $x_{i 0} . w$ is a variable indicating the number of weeks since each treated individual began receiving his/her treatment. $w=0$ in the week when the treatment started, and is negative for weeks before that. $d_{w i t}$ is a dummy variable equal to 1 in period $t$ if an individual started receiving their treatment $w$ periods ago. For example, for an individual assigned to receive the transport treatment from week 15 of 
the study onwards, the dummy $d_{0 i t}$ is equal to 1 in week 15 and to 0 in all other weeks. ${ }^{23}$ Individuals in the control group have all such dummy variables set to 0 . Thus, $\beta_{g w}$ is our estimate of the impact of intervention $g, w$ weeks after the intervention started.

Second, we estimate the trajectory of treatment effects by pooling all post treatment $(w>0)$ time observations together and estimating quadratic trends over time of the treatment effect for each intervention. ${ }^{24}$ To do this, we estimate equation 3 , subject to quadratic constraints on $\beta_{g w}$ and $\gamma_{s w}$, and to the assumption that no treatment has an effect before it commences.

$$
\begin{aligned}
y_{i t c} & =\eta_{t}+\sum_{g=1}^{4} \sum_{w=S_{g}}^{E_{g}} \beta_{g w} \cdot \text { treat }_{g i} \cdot d_{w i t} \\
& +\sum_{s=1}^{2} \sum_{w=S_{s}}^{E_{s}} \gamma_{s w} \cdot \text { spillover }_{s i} \cdot d_{w i t}+\alpha_{t} \cdot y_{i t c, p r e}+\boldsymbol{\delta} \cdot \boldsymbol{x}_{i 0}+\mu_{i t c}
\end{aligned}
$$

subject to:

$$
\begin{gathered}
\beta_{g w}= \begin{cases}0 & \text { if } w \leq 0 \\
\phi_{g 0}+\phi_{g 1} \cdot w+\phi_{g 2} \cdot w^{2} & \text { if } w>0\end{cases} \\
\text { and } \gamma_{s w}= \begin{cases}0 & \text { if } w \leq 0 \\
\theta_{s 0}+\theta_{s 1} \cdot w+\theta_{s 2} \cdot w^{2} & \text { if } w>0\end{cases}
\end{gathered}
$$

That is, instead of estimating parameters $\beta_{g w}$ and $\gamma_{s w}$, we will estimate $\phi_{g 0}, \phi_{g 1}, \phi_{g 2}, \theta_{s 0}$, $\theta_{s 1}$ and $\theta_{s 2}$.

23 Similarly, for an individual who starts treatment in week 15 , we set $d_{-1 i 14}=1$, and $d_{5 i 20}=1$, and so on. Note that because interventions ran for different lengths of time, the number of weeks for which we will be able to estimate the treatment effect relative to the start week of the treatment will differ by treatment. In the notation above $S_{g}$ denotes the earliest week for which we will be able to estimate a treatment effect for treatment or spillover group $g$. $E_{g}$ denotes the final week. If, for example, a treatment began in week 15 of the study, then $S_{g}=-15$ and $E_{g}=39$. For this treatment, we will use data from week 10 of the study to estimate the coefficient $\beta_{g-5}$.

${ }^{24}$ In the pre-analysis plan, we had originally intended to include $w=0$ in the quadratic fit. On reflection, it is preferable to allow the treatment effect to begin the week after treatment begins. 


\subsubsection{Effects on job search intensity}

We find that the transport intervention increases the intensity of search. In the weeks when treatment is available, treated individuals are about 25 percentage points more likely to search for a vacancy at the job board - a form of job search that requires transport. This represents a fivefold increase over individuals in the control group. ${ }^{25}$ In the same period, treated individuals are about 12.5 percent more likely to be doing any job search activity than control individuals (a 5 percentage point effect over a control mean of 0.4). This effect decreases linearly after the transport intervention ends. In the model where we impose quadratic constraints, we are able to estimate a significant effect on job search at least 2 months after the end of the intervention. The job application workshop, on the other hand, does not affect the likelihood of searching for a job. Figures figures 7, 8 and 9 illustrate these findings.

We find that study participants temporarily decrease the amount of work they take during weeks when the transport subsidy is available (figure 10). The effect is driven by a reduction of work in self-employment (figure 11). Franklin (2015) finds a similar effect of transport subdisies for a sample of active jobseekers.

More frequent search activity does not translate in a higher number of job applications for individuals in the transport group. On average, individuals in the control group place 1.3 applications for temporary jobs and 2.3 applications for permanent jobs in the 12 months before the endline interview. As shown in table 4, these numbers are not significantly different for either the transport or the workshop interventions.

$<$ Figure 7 here. $>$

$<$ Figure 8 here. $>$

$<$ Figure 9 here. $>$

$\overline{25}$ Throughout the course of phone survey, an average of 5 percent of control individuals search at the job boards in any given week. 


\section{< Figure 10 here. >}

\subsubsection{Effects on search efficacy}

Our treatments significantly increase the efficacy of job search for the high impact groups described above. In the full sample, control respondents receive a job offer of permanent employment every 6.1 applications. Respondents in the two treatment groups receive an offer nearly every 4 applications. These effects, described in table 4 are however not statistically significant. Focusing on high-school graduates, one of the high-impact groups of the intervention, reveals stronger and statistically significant effects. Control individuals with a high school degree receive an offer for a permanent job every 10.6 applications. Both interventions reduce that figure to 5.2 applications, a very large impact. In the discussion section we present more analysis that allows us to understand what drives the increased search efficacy among workers with only secondary education. The next section rules out the possibility that this is due to a change in the types of jobs they search for after the intervention.

\subsubsection{Effects on the types of jobs sought by study participants}

We do not find evidence suggesting that treated individuals search for different jobs compared to individuals in the control group. We test this hypothesis in three different ways. First, we use self-reported data on reservation wages and find that treated individuals report being willing to work for the same wages as control individuals. ${ }^{26}$ This holds on average, as well as within educational categories ( see table 20 and figure 20 in the appendix). Second, in the endline survey we ask individuals whether they stopped searching for some occupation in the previous 12 months. This question was aimed at capturing jobseekers' discouragement. We find that individuals in the three experimental groups are equally likely to give up searching for at least one occupation and to stop searching for white col-

\footnotetext{
26 This is consistent with the fact that average earnings are similar across experimental groups, as discussed above. Quantile regression analysis further confirms that the interventions did not affect earnings at the bottom of the distribution.
} 
lar jobs. Finally, in figures 1 and 2 we compare the probability of working in a number of different occupations across the three groups. Occupation profiles look similar for the three groups, with a slight shift towards white collar jobs for individuals in the transport and workshop groups. Overall, this evidence suggests that treated individuals look for similar occupations and are willing to work for similar wages. The effects on job search efficacy are thus unlikely to be driven by jobseekers' decision to search for 'easier-to-get' permanent and formal jobs.

\subsection{Indirect effects on untreated jobseekers}

In this section, we study the outcomes of untreated jobseekers who live close to program participants. The benefits of the interventions can extend to this group if the young jobseekers who are offered the programs share information, job referrals or resources with friends and acquaintances in the same neighbourhood. Information and risk sharing of this kind have been documented in several recent studies on developing countries' labour markets (Angelucci and De Giorgi, 2009; Magruder, 2010). ${ }^{27}$ On the other hand, untreated youth living close to program recipients can experience negative effects if these groups compete for scarce jobs in the same neighbourhood.

As explained in the design section, some eligible respondents living in clusters assigned to treatment are not offered the program. This is a 'partial population experiment' (Moffitt et al., 2001), which allows us to compare untreated individuals living close to program participants to untreated individuals living in clusters where no jobseeker has been offered the program. We report the results of this analysis in columns 4 and 5 of table 3.

We do not find statistically significant differences between untreated individuals living in geographical clusters assigned to one of the two interventions and untreated individuals in pure control clusters. However, we are less powered to detect indirect effects compared to the direct effects we studied above. For example, we estimate that untreated individuals in clusters assigned to the job application workshop experience an increase in the proba-

\footnotetext{
27 The descriptive evidence from our surveys further confirms that social networks are an important source of information about work opportunities and are used extensively for job referrals.
} 
bility of formal work of 5.6 percentage points. This effect is of the same magnitude as the treatment effect we estimate on individuals who are offered the job application workshop, but it is not statistically significant.

We also randomly vary the proportion of individuals treated in the clusters that received the transport intervention. This allows us to run a regression of the form:

$$
\begin{aligned}
y_{i c}= & \kappa+\beta_{20} \cdot S_{20 c} \cdot C_{i}+\beta_{40} \cdot S_{40 c} \cdot C_{i}+\beta_{75} \cdot S_{75 c} \cdot C_{i}+\beta_{90} \cdot S_{90 c} \cdot C_{i} \\
& +\gamma_{20} \cdot S_{20 c} \cdot \mathrm{T}_{i}+\gamma_{40} \cdot S_{40 c} \cdot \mathrm{T}_{i}+\gamma_{75} \cdot S_{75 c} \cdot \mathrm{T}_{i}+\gamma_{90} \cdot S_{90 c} \cdot \mathrm{T}_{i} \\
& +\alpha \cdot y_{i c, p r e}+\boldsymbol{\delta} \cdot \boldsymbol{x}_{i 0}+\mu_{i c} .
\end{aligned}
$$

where the sample is restricted to individuals in clusters assigned to pure control and clusters assigned to the transport intervention. $T_{i}$ identifies individuals who have been assigned to the transport treatment, while $C_{i}$ identifies individuals who have not been assigned to the transport treatment. $S_{20 c}$ is a dummy variable for individuals living in a cluster where $20 \%$ of individuals were offered the transport treatment. Thus, $\beta_{20}$ captures the difference in outcomes between untreated individuals in these clusters and untreated individuals in clusters where nobody was treated. Further, $\gamma_{20}$ measures the difference in outcomes between treated individuals in $S_{20 c}$ clusters and untreated individuals in untreated clusters. $S_{40 c}, S_{75 c}, S_{90 c}$, and the remaining $\beta$ and $\gamma$ coefficients have a similar interpretation.

The indirect effects of the transport treatment depend on the level of saturation. As the transport intervention has direct impacts on permanent and formal work, we first study indirect impacts on these two dimensions. In figures 12 and 13 we present estimates from model 6. We document a positive indirect effect for control individuals in clusters with 25 (40) percent saturation for written agreement (permanent work). We also document that untreated individuals in clusters with 90 percent saturation are 5.6 percentage points less 
likely to be in permanent employment than individuals in pure control clusters. ${ }^{28}$

\section{Discussion: What constraints did the interventions relax?}

In this section, we present some additional analysis to explore the nature of the constraints faced by the jobseekers in our study and the extent to which the interventions relaxed these constraints. ${ }^{29}$

\subsection{Spatial constraints}

We have argued that high transport costs make job search difficult for the young unemployed. These costs are particularly high for individuals that live far away from the centre of the city. If transport costs are indeed a barrier to job search, these individuals may be more likely to work in sectors of 'last resort' compared to those residing closer to the centre of the city. Some forms of self-employment are thought to be sectors of 'last resort' (Falco and Haywood, 2016). Further, if our interventions relax this spatial constraint to job search, we expect to observe a weaker spatial pattern in employment outcomes among treated individuals. We investigate these hypotheses by computing the smoothed local polynomial estimate of the relationship between distance from the city centre and various for of employment.

We find that in the control group the probability of being self-employed increases almost linearly with distance from the city centre. The probability of having any employment, on the other hand, does not change with distance. This suggests that spatial barriers influence the occupational structure of the urban labour market and is consistent with a model where high transport costs distort job search. This finding complements recent work on the effect of transportat costs on the occupational structure in villages (Asher and Novosad, 2015).

28 For the regression on permanent work we can reject the null hypothesis that all $\beta$ coefficients are equal to 0 .

29 The analysis in this section was not registered in the pre-analysis plan. 
Most importantly, we find that the transport intervention eliminates the spatial patterns of self-employment observed in the control group. Figure 17 shows that in the transport group, individuals who reside far from the city centre have the same probability of being in self-employment as individuals who live close to the centre of the city. Regression results with differential effects of distance by group (either linear or quadratic) confirm that the transport treatment significantly alters the effect of distance. These regressions confirm that lowering the monetary cost of transport to the city centre removes the spatial influence on the probability of self-employment: the effect of distance is statistically indistinguishable from zero for the treatment group.

\section{< Figure 17 here. >}

Figure 18 in the appendix shows that the job application workshop similarly mitigates the effects of space on the probability of self employment. Individuals in this experimental group do not search more intensely, but become more effective in job search. This suggests that effects of space can also be mitigated by improving search efficacy.

\subsection{Information constraints}

Did our interventions enable the labour market to separate more effectively high skilled workers from low skilled workers? To address this question we exploit the detailed data from the personnel selection tests. For each test, we regress individual test scores on a rich set of covariates, including demographic characteristics, educational achievement, and the work history of study participants. We choose this set of variables because they can be readily signalled to an employer using a $\mathrm{CV}$, a cover letter, or during the course of an interview. Using the estimated coefficients, we obtain predicted test scores for all individuals in our sample. Our objective is to study how predicted skills correlate with labour market outcomes in different experimental groups.

Suppose that the job application workshop has no effect on participants' ability to sig-

nal their skills to employers. In that case, we would expect the same correlation between 
predicted test scores and employment outcomes in the treatment and control groups. In contrast, suppose that the job application workshop allows individuals to signal their skills more effectively. In this scenario, we expect to find a larger positive correlation between predicted test scores and employment outcomes among individuals invited to the workshop, compared to the control group. That is, we expect the workshop to be particularly useful for individuals with strong observable characteristics, who can benefit from being more able to convey their attractive employment characteristics.

Our results suggest the the ability to signal skills has improved for low-education jobseekers - the group which experienced the strongest effects from the job application workshop. In this group, the correlation between predicted skills and having a permanent job is significantly stronger among individuals invited to the workshop compared to the control condition. We also estimate that the correlation between predicted skills and earnings increases, although insignificantly so. We report this analysis in table 27 and figure 15 . We are unable to find similar effects when comparing low education jobseekers in the transport group to low education jobseekers in the control condition. ${ }^{30}$ So this effect is unique to the job application workshop.

We also find that, among low-education individuals in the control group, high predicted skills are not associated with better labour market outcomes (see table 27). The labour market for workers with low levels of education does not seem to separate jobseekers on basis of the skills which we measure through our tests. This separation occurs, however, after we introduce the job application workshop program.

To measure predicted skills, we used characteristics that could be easily included in a $\mathrm{CV}$, cover letter, or discussed in an interview. The orientation component of the job application workshop is aimed at making workers more effective in this part of the application process. Thus the results reported in this section suggest a positive effect of the orientation component. Skills certification, on the other hand, should enable workers to signal skills that are 'hard to observe', and not necessarily correlated with jobseekers' observable characteristics. Does the additional information revealed in the certificates allow individuals to $\overline{30}$ This result is not reported, but is available upon request. 
improve their employment outcomes? We turn to this question in the next section.

\subsubsection{The role of certification}

We look for evidence that the certification component of the workshop leads to better employment outcomes for individuals who scored well on the tests. To this end, we employ a regression discontinuity design. The certificates issued to respondents report test scores in discrete bands. The original test score is not reported on the certificates and it not disclosed to study participants. This allows us to study the impact of being placed in a higher band, controlling for the original test score. The intuition behind this test is simple: if the information that we disclose is driving at least part of the treatment effect, we would expect a discrete improvement in outcomes when individuals are placed in a higher band.

We perform this analysis for the aggregate score and the Raven test score since we find that these measures have the strongest predictive power for endline employment outcomes. Scores below the median were lumped together into a bottom band, while individuals scoring above the median were divided into five bands for each of the higher deciles of the test score distribution. We implement local linear regression to control for raw test scores on either side of the cut-offs, iteratively moving across all 5 relevant cut-offs. We use the optimal bandwidth selection rule suggested by Imbens and Kalyanaraman (2012), but all results are consistent with different bandwidth selections. ${ }^{31}$

We find no evidence that scoring in a higher band, across any of the test scores, leads to a significant improvement in employment outcomes, relatively to individuals scoring in a lower band, once we control for the test score itself. Notably this is true for the two main outcomes of job quality used in the paper so far: permanent work, and work with a written agreement. Figure 16 illustrates this result, by showing the effect of being above the median aggregate test score on having a permanent job. The full set of results, using

\footnotetext{
31 The optimal bandwidth selection is performed using the Stata command given by Nichols (2007). The selected bandwidth differs across test outcomes and band cut-offs. For example the optimal bandwidth for the aggregate test score at the 50th percentile is 0.62 , where the median of the aggregate score is 4.843 with standard deviation of 0.88 . In cases where the selected bandwidth is larger than the reported test score band itself, we check that the results are robust to restricting the bandwidth to the range within the marks band.
} 
optimal and other bandwidth selections, is available on request.

\section{$<$ Figure 16 here. $>$}

We interpret these results as suggestive evidence that the information about 'hardto-observe' skills carried by the certificates is not crucial in driving the effect of the job application workshop. Rather, the intervention helps workers improve the way they signal observable skills. Two further pieces of evidence corroborate these conclusions. First, self-reported data on the use of the certificates indicates that about 58 percent of the respondents who received the certificate and made at least one job application did not show the certificate to their prospective employer. Second, the residuals from a regression of test scores on observable characteristics (a rough proxy for unobservable workers' abilities) do not correlate positively with employment outcomes. In sum, while the job application workshop increased workers' capacity to signal their easier-to-observe skills, helping employers separate workers on the basis of idiosyncratic and hard-to-observe skills is more challenging.

\section{Conclusions}

Cities in the developing world are growing at an unprecedented pace. A key challenge for policy makers is to identify effective interventions to support the large number of individuals who find it hard to access urban labour markets: the young, women and those without tertiary education. In this paper, we conduct a randomised evaluation of two interventions to improve the labour market prospects of young Ethiopian jobseekers. The first intervention is a transport subsidy that covers the cost of travelling to the centre of the

city to look for employment. The second intervention is a job application workshop with two components: certification of skills and orientation on how to make effective job applications through $\mathrm{CVs}$, cover letters, and interviews. We hypothesised that the programs would enable jobseekers to search more intensely and more effectively, resulting in improved employment outcomes. A fortnightly panel of short phone interviews allows us to 
study these mechanisms in detail. We also randomised the proportion of treated jobseekers within geographical clusters to study the effects of non-participants residing in program localities.

We find that both interventions help jobseekers to secure better jobs. Individuals who are offered the job application workshop are 30 percent more likely to have a permanent job, and nearly 25 percent more likely to have a formal job than individuals in the control group. The transport subsidy leads to a 25 percent increase in formal employment. These effects are statistically significant and robust to a correction for multiple comparisons. Impacts are concentrated among the socio-demographic groups that have the worst employment outcomes at baseline: women and those with at most secondary education.

On average, we do not find indirect effects on untreated individuals living in the proximity of treated ones. Exploring variation in the intensity of the transport treatment across areas, we find some positive impacts on the job quality of untreated neighbours when the proportion of treated jobseekers is low and some negative effects when that proportion is very high $(90 \%)$.

Detailed analysis based on a high-frequency phone survey reveals that the interventions operate through the hypothesised mechanisms. The transport intervention allows jobseekers to search more intensely, while search efficacy improves for jobseekers in both the transport and the workshop groups. We also find that both interventions relax spatial constraints on occupational choices. The job application workshop also overcomes a crucial informational barrier by allowing low educated workers to better signal their skills to employers and earn higher returns on them. These results suggest that interventions of this kind can ease spatial constraints on job search and correct information asymmetries that may damage workers' prospects when ability cannot be easily signalled.

In conclusion, this paper shows that active labour market programs can improve the employment outcomes of urban jobseekers in developing countries, and especially the most disadvantaged: the young, women, and those without tertiary education. Exploring whether job-search support can be successfully bundled with interventions that in- 
crease workers' cognitive and non-cognitive skills (Card et al., 2011; Attanasio et al., 2011; Blattman et al., 2015; Ghosal et al., 2015; Heller et al., 2015; Hirshleifer et al., 2015) and how to best coordinate programs that assist job search and programs that foster entrepreneurship (Blattman et al., 2013; Fafchamps et al., 2014; Fafchamps and Quinn, 2015) are interesting avenues for future research. 


\section{References}

Abebe, G., S. Caria, P. Falco, M. Fafchamps, S. Franklin, and S. Quinn (2015). Addis Ababa Firm Survey.

African Economist (2012). 50 largest cities in africa.

Angelucci, M. and G. De Giorgi (2009). Indirect Effects of an Aid Program: How do Cash Transfers Affect Ineligibles' Consumption? The American Economic Review, 486-508.

Asher, S. and P. Novosad (2015). Market Access and Structural Transformation: Evidence from Rural Roads in India. Working Paper.

Attanasio, O., A. Kugler, and C. Meghir (2011). Subsidizing Vocational Training for Disadvantaged Youth in Colombia: Evidence from a Randomized Trial. American Economic Journal: Applied Economics, 188-220.

Baird, S., C. McIntosh, and B. Özler (2011). Cash or Condition? Evidence from a Cash Transfer Experiment. The Quarterly Journal of Economics.

Beaman, L., N. Keleher, and J. Magruder (2013). Do Job Networks Disadvantage Women? Evidence from a Recruitment Experiment in Malawi. Working Paper.

Benjamini, Y., A. M. Krieger, and D. Yekutieli (2006). Adaptive Linear Step-up Procedures that Control the False Discovery Rate. Biometrika 93(3), 491-507.

Blattman, C., N. Fiala, and S. Martinez (2013). Generating Skilled Self-Employment in Developing Countries: Experimental Evidence from Uganda. Quarterly Journal of Economics.

Blattman, C., J. C. Jamison, and M. Sheridan (2015). Reducing Crime and Violence: Experimental Evidence on Adult Noncognitive Investments in Liberia.

Bowles, S., H. Gintis, and M. Osborne (2001). Incentive-Enhancing Preferences: Personality, Behavior, and Earnings. The American Economic Review 91(2), 155-158.

Bruhn, M. and D. McKenzie (2009). In Pursuit of Balance: Randomization in Practice in Development Field Experiments. American Economic Journal: Applied Economics 1(4), 200-232.

Bryan, G., S. Chowdhury, and A. M. Mobarak (2014). Underinvestment in a Profitable Technology: The Case of Seasonal Migration in Bangladesh. Econometrica 82(5), 16711748.

Bryan, G. and M. Morten (2015). Economic Development and the Spatial Allocation of Labor: Evidence from Indonesia. Working Paper.

Card, D., R. Chetty, and A. Weber (2007). Cash-on-Hand and Competing Models of Intertemporal Behavior: New Evidence from The Labor Market. Quarterly Journal of Economics 122(4). 
Card, D., P. Ibarrarán, F. Regalia, D. Rosas-Shady, and Y. Soares (2011). The Labor Market Impacts of Youth Training in the Dominican Republic. Journal of Labor Economics 29(2), 267-300.

Caria, S. (2015). Choosing Connections. Experimental Evidence from a Link-Formation Experiment in Urban Ethiopia. Working Paper.

Chamorro-Premuzic, T. and A. Furnham (2010). The Psychology of Personnel Selection. Cambridge University Press.

Chetty, R. (2008). Moral Hazard versus Liquidity and Optimal Unemployment Insurance. Journal of political economy 116(2), 173-234.

Clark, A. E. and A. J. Oswald (1994). Unhappiness and unemployment. The Economic Journal 104(424), 648-659.

Crépon, B., E. Duflo, M. Gurgand, R. Rathelot, and P. Zamora (2013). Do Labor Market Policies have Displacement Effects? Evidence from a Clustered Randomized Experiment. The Quarterly Journal of Economics 128(2), 531-580.

CSA (2014). Key Findings on the 2014 Urban Employment Unemployment Survey.

Dal Bó, E., F. Finan, and M. A. Rossi (2013). Strengthening State Capabilities: The Role of Financial Incentives in the Call to Public Service. The Quarterly Journal of Economics 128(3), 1169-1218.

Davison, W. (2014, August). Addis Ababa Doubling in Size Gives Africa Another Hub. Bloomberg.

Fafchamps, M., D. McKenzie, S. Quinn, and C. Woodruff (2014). Microenterprise Growth and the Flypaper Effect: Evidence from a Randomized Experiment in Ghana. Journal of development Economics 106, 211-226.

Fafchamps, M. and S. Quinn (2015). Aspire. Technical report, NBER Working Paper.

Falco, P. and L. Haywood (2016). Entrepreneurship versus Joblessness: Explaining the Rise in Self-Employment. Journal of Development Economics 118, 245-265.

Fisman, R., P. Jakiela, and S. Kariv (2015). How did distributional preferences change during the great recession? Journal of Public Economics 128, 84-95.

Franklin, S. (2015). Location, Search Costs and Youth Unemployment: A Randomized Trial of Transport Subsidies in Ethiopia. CSAE Working Paper WPS/2015-11.

Ghosal, S., S. Jana, A. Mani, S. Mitra, and S. Roy (2015). Sex Workers, Self-Image and Stigma: Evidence from Kolkata Brothels. Working Paper.

Gollin, D. and R. Rogerson (2010). Agriculture, Roads, and Economic Development in Uganda. NBER Working Paper. 
Groh, M., N. Krishnan, D. J. McKenzie, and T. Vishwanath (2012). Soft Skills or Hard Cash? The Impact of Training and Wage Subsidy Programs on Female Youth Employment in Jordan. World Bank Policy Research Working Paper (6141).

Groh, M., D. McKenzie, N. Krishnan, and T. Vishwanath (2016). The Impact of Soft Skills Training on Female Youth Employment: Evidence from a Randomized Experiment in Jordan.

Groh, M., D. McKenzie, N. Shammout, and T. Vishwanath (2015). Testing the Importance of Search Frictions and Matching Through a Randomized Experiment in Jordan. IZA Journal of Labor Economics 4(1), 1-20.

Heckman, J. J., J. Stixrud, and S. Urzua (2006). The Effects of Cognitive and Noncognitive Abilities on Labor Market Outcomes and Social Behavior. NBER Working Paper.

Heller, S. B., A. K. Shah, J. Guryan, J. Ludwig, S. Mullainathan, and H. A. Pollack (2015). Thinking, Fast and Slow? Some Field Experiments to Reduce Crime and Dropout in Chicago.

Hirshleifer, S., D. McKenzie, R. Almeida, and C. Ridao-Cano (2015). The Impact of Vocational Training for the Unemployed: Experimental Evidence from Turkey. The Economic Journal.

Imbens, G. and K. Kalyanaraman (2012). Optimal bandwidth choice for the regression discontinuity estimator. Review of Economic Studies 79(3).

Jensen, R. (2012). Do Labor Market Opportunities Affect Young Women's Work and Family Decisions? Experimental Evidence from India. The Quarterly Journal of Economics.

Kaas, L. and P. Kircher (2015, October). Efficient Firm Dynamics in a Frictional Labor Market. American Economic Review 105(10), 3030-60.

Magruder, J. R. (2010). Intergenerational Networks, Unemployment, and Persistent Inequality in South Africa. American Economic Journal: Applied Economics 2(1), 62-85.

Moffitt, R. A. et al. (2001). Policy Interventions, Low-Level Equilibria, and Social Interactions. Social dynamics 4(45-82), 6-17.

Nichols, A. (2007, November). RD: Stata module for regression discontinuity estimation. Statistical Software Components, Boston College Department of Economics.

OECD (2013). OECD Skills Outlook 2013: First Results from the Survey of Adult Skills. OECD Publishing.

OECD (2015). OECD Employment Outlook 2015.

Pallais, A. (2014). Inefficient Hiring in Entry-Level Labor Markets. The American Economic Review 104(11), 3565-3599.

Phillips, D. C. (2014). Getting to Work: Experimental Evidence on Job Search and Transportation Costs. Labour Economics 29, 72-82. 
Pierre, G., M. L. Sanchez Puerta, A. Valerio, and T. Rajadel (2014). STEP Skills Measurement Surveys: Innovative Tools for Assessing Skills.

Raven, J. (2000). The Raven's Progressive Matrices: Change and Stability over Culture and Time. Cognitive psychology 41(1), 1-48.

Schmidt, F. L. and J. E. Hunter (1998). The Calidity and Utility of Selection Methods in Personnel Psychology: Practical and Theoretical Implications of 85 Years of Research Findings. Psychological bulletin 124(2), 262.

Serneels, P. (2007). The Nature of Unemployment Among Young Men in Urban Ethiopia. Review of Development Economics 11(1), 170-186.

United Nations (2014). World Urbanization Prospects 2014. United Nations Publications. 


\section{Tables and Figures for Insertion in Text}

Figure 1: Most Common Occupations: Control Group and Job Application Workshop Group

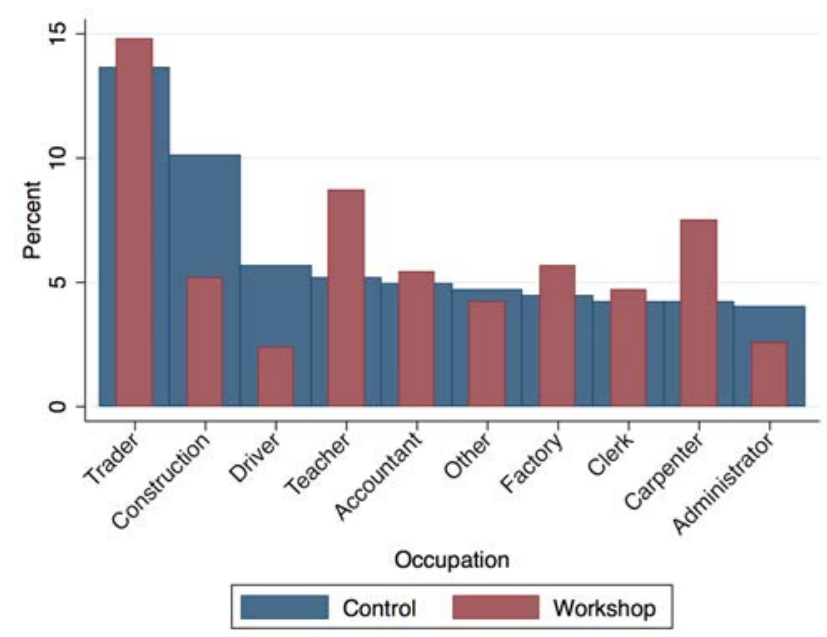

Figure 2: Most Common Occupations: Control Group and Transport Subsidy Group

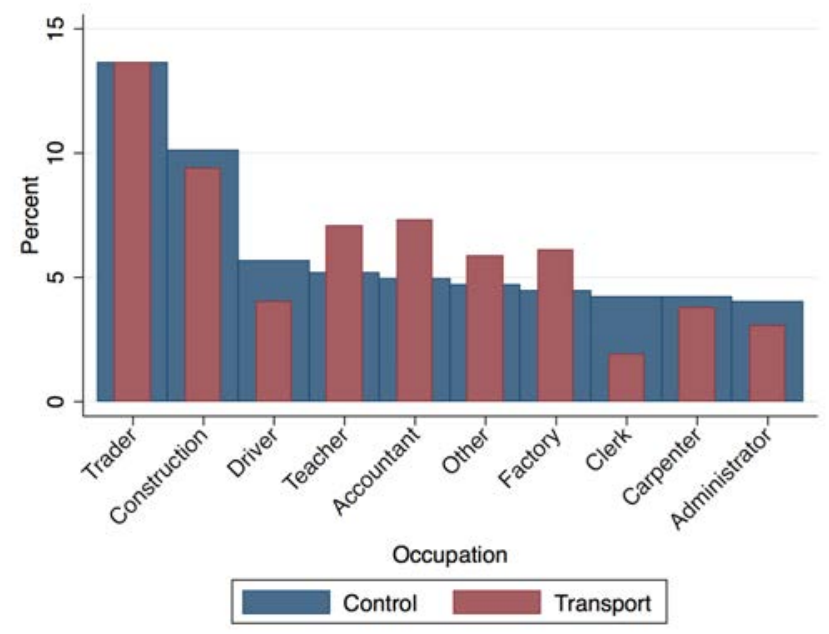


Figure 3: Heterogeneous Impacts by Education: Permanent Work

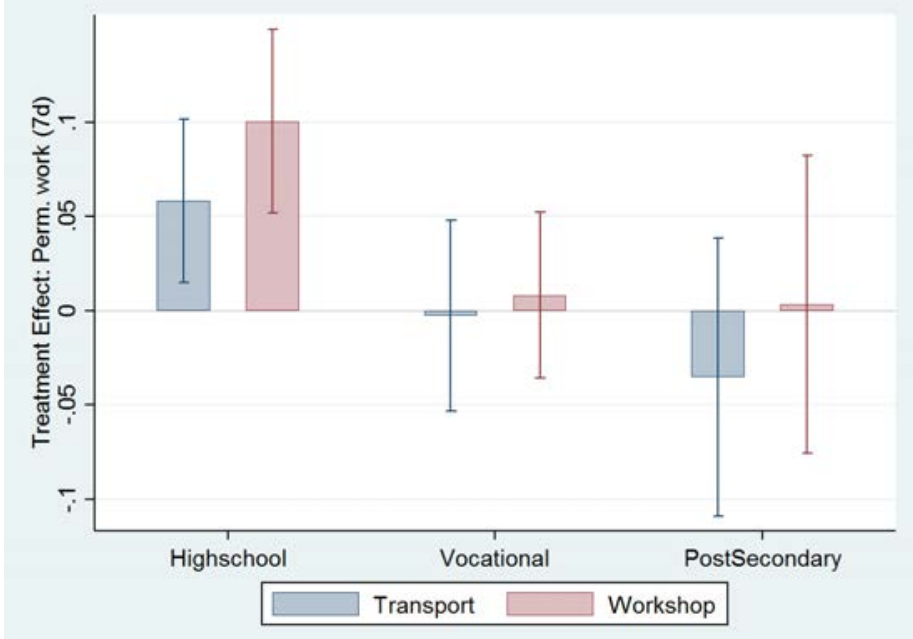

Figure 4: Heterogeneous Impacts by Education: Work with written Agreement

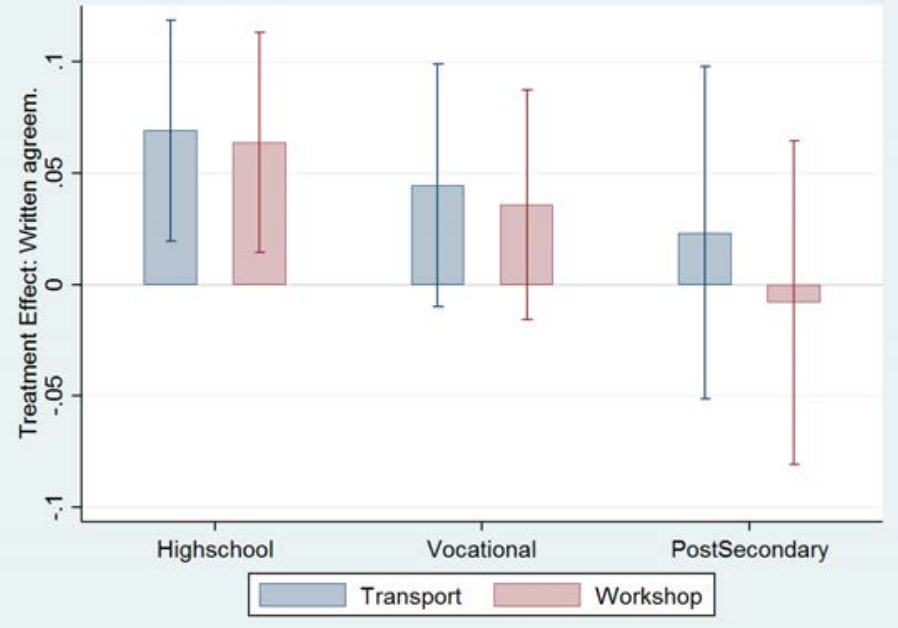


Figure 5: Heterogeneous Impacts by Gender: Permanent Work

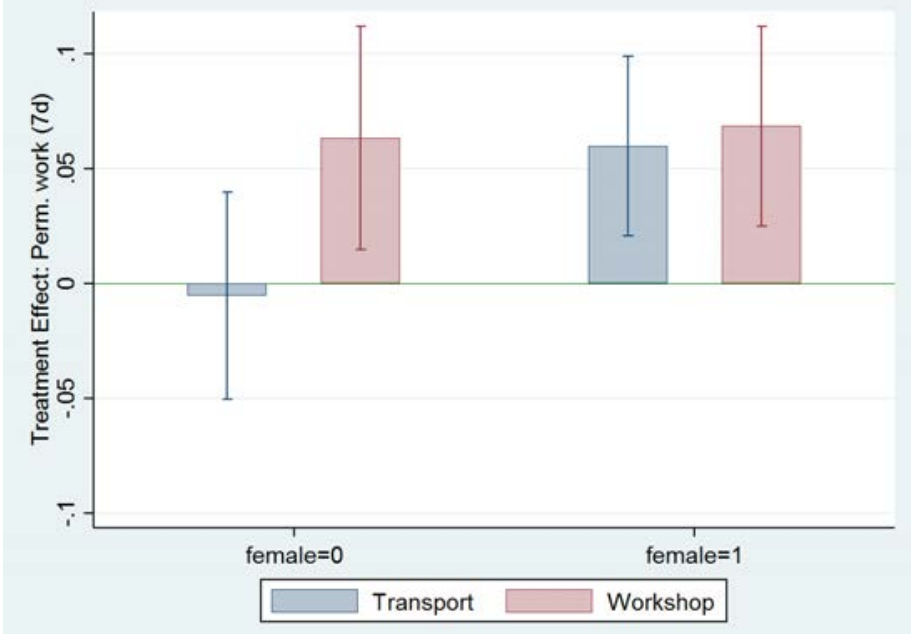

Figure 6: Heterogeneous Impacts by Gender: Work with written Agreement

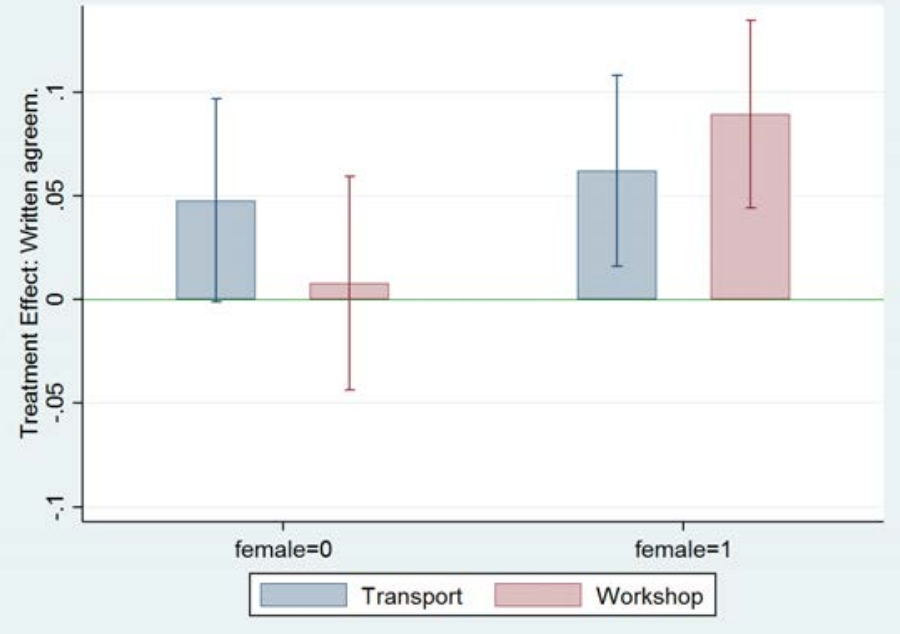


Figure 7: Trajectory of Impact on Job Search at the Job Boards: Transport Treatment

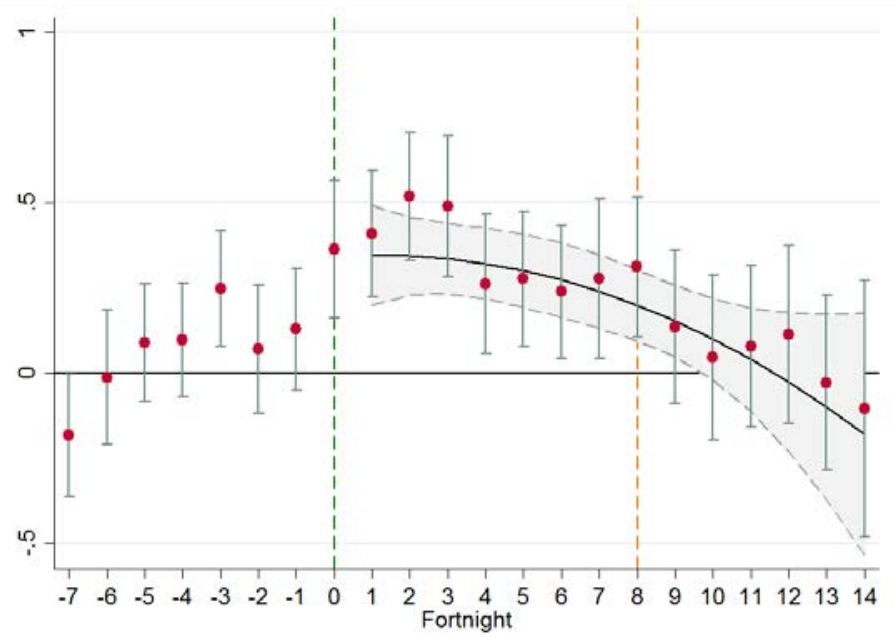

Figure 8: Trajectory of Impact on Job Search: Transport Treatment

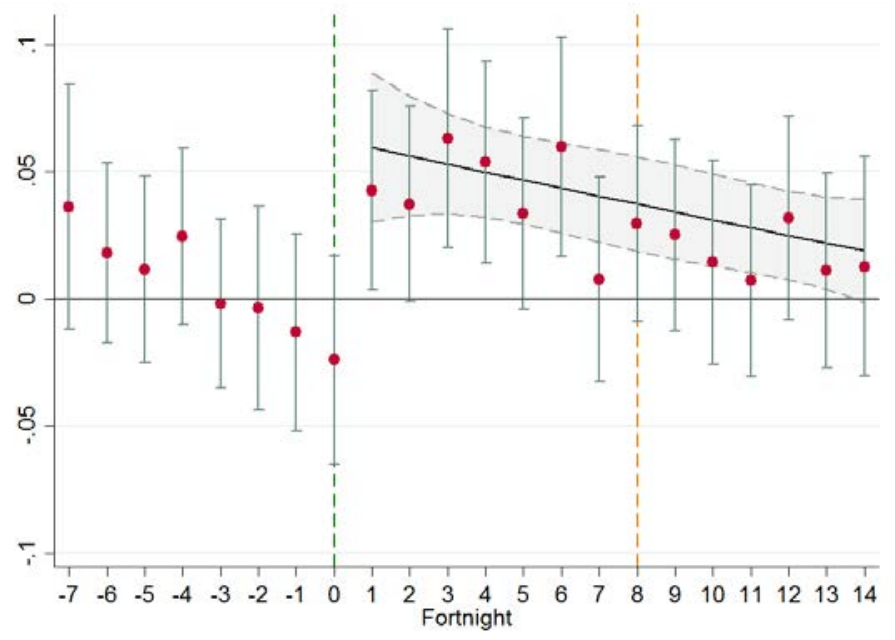


Figure 9: Trajectory of Impact on Job Search: Job application workshop

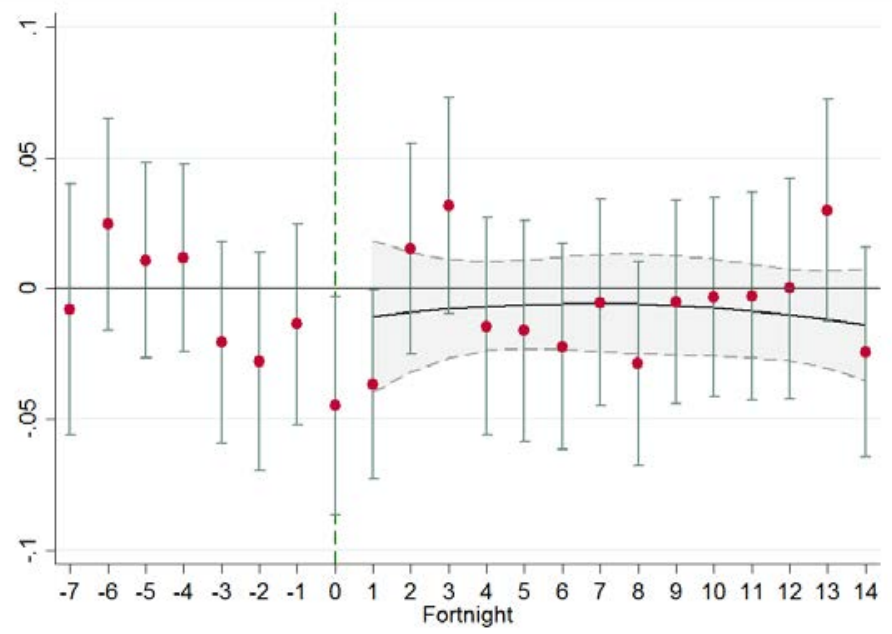

Figure 10: Trajectory of Impact on Employment: Transport Treatment

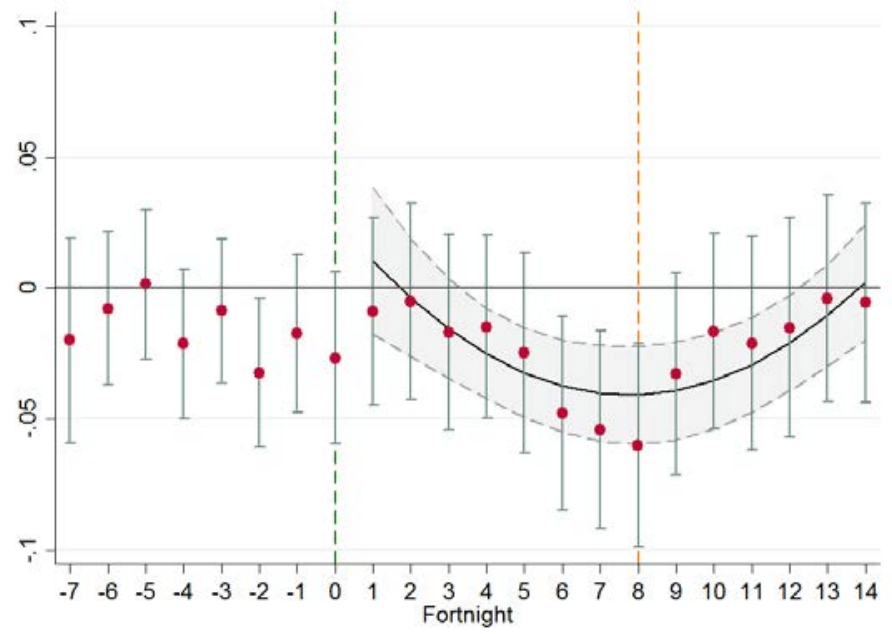


Figure 11: Trajectory of Impact on Self-Employment: Transport Treatment

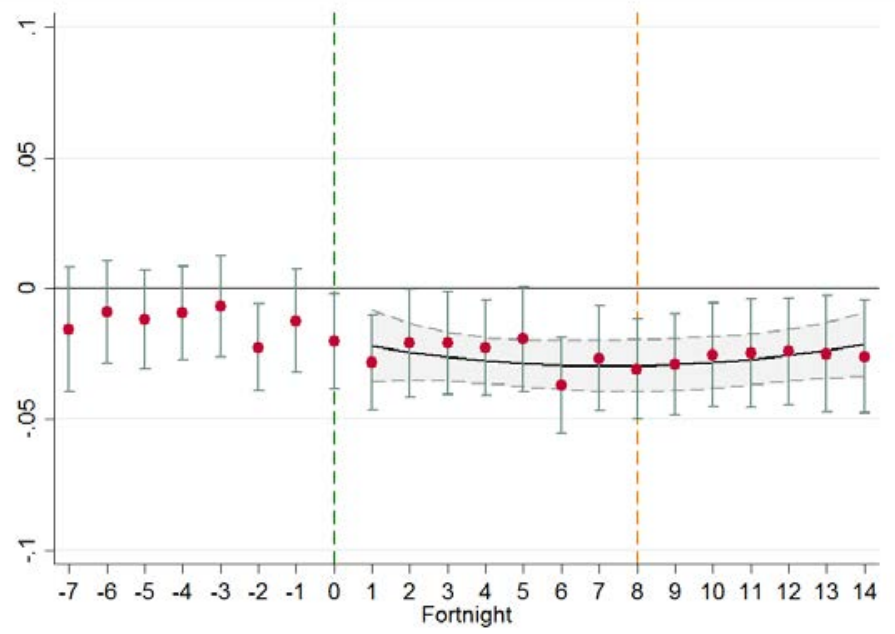

Figure 12: Randomized saturation: Permanent work

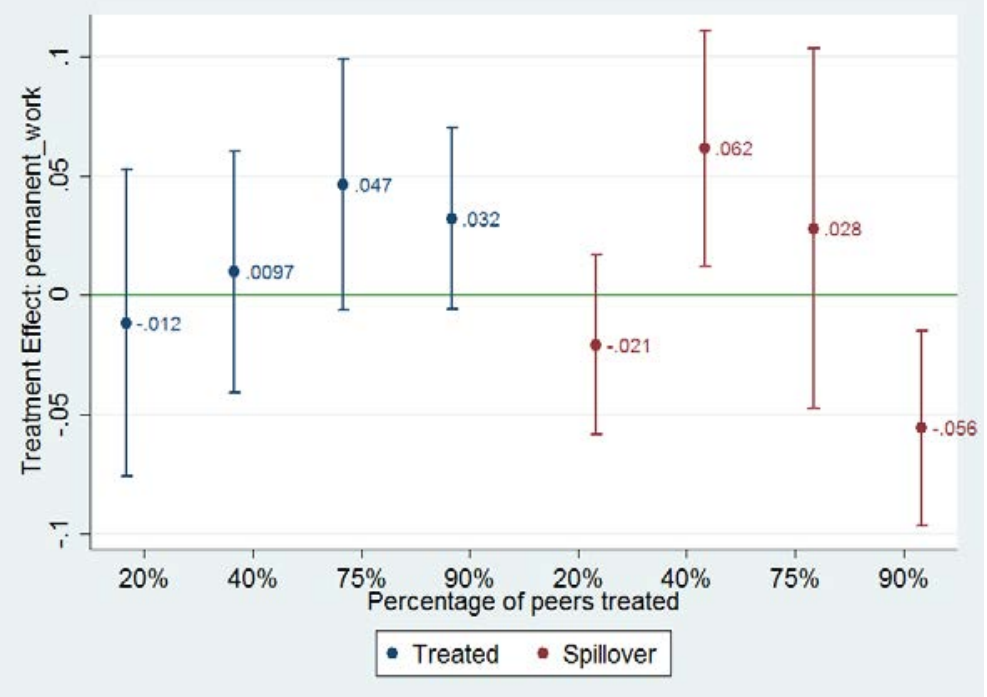


Figure 13: Randomized saturation: Written agreement

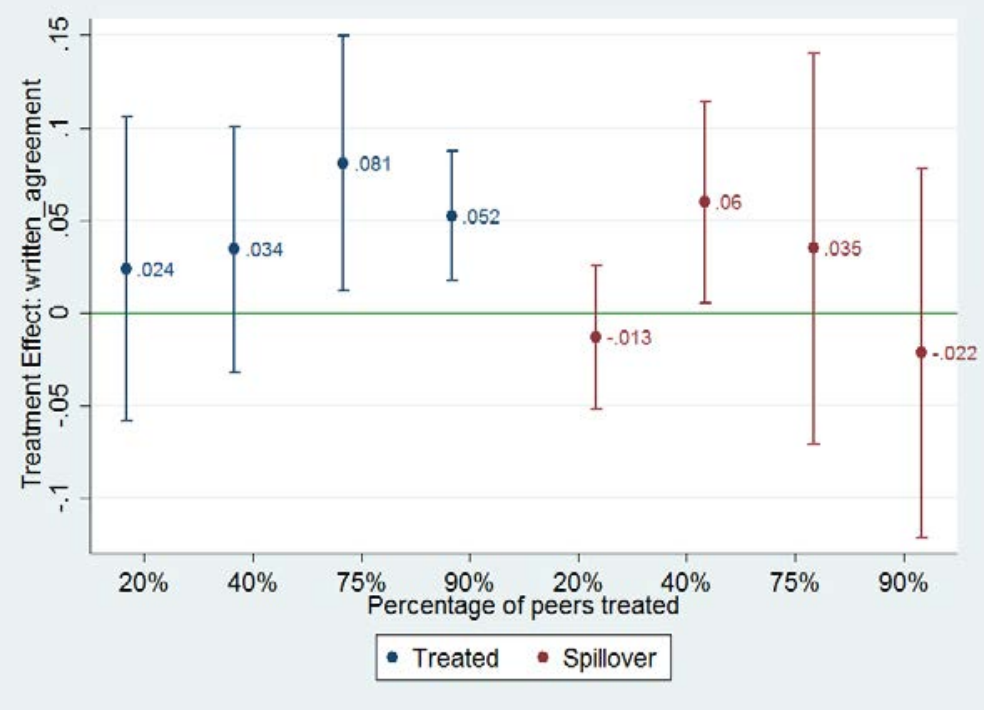


Figure 14: Predicted grades and permanent work: all jobseekers

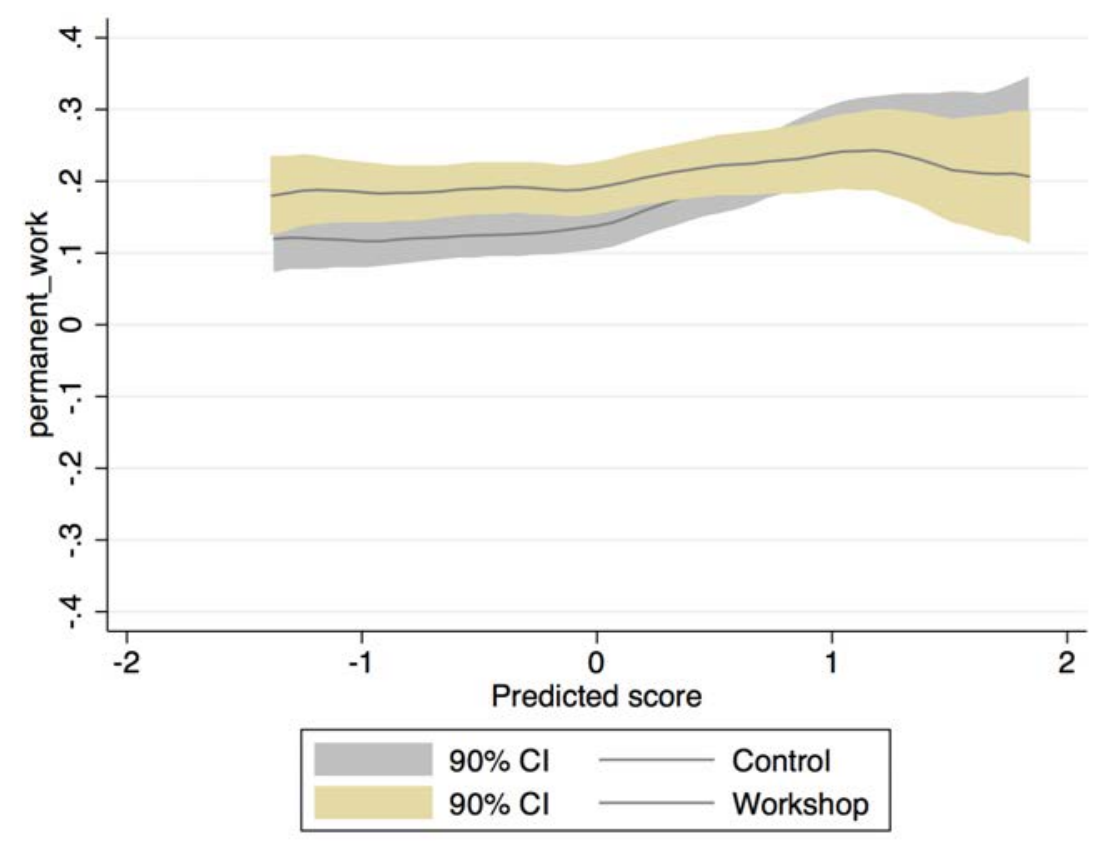

Figure 15: Predicted grades and permanent work: job seekers with at most a high school degree

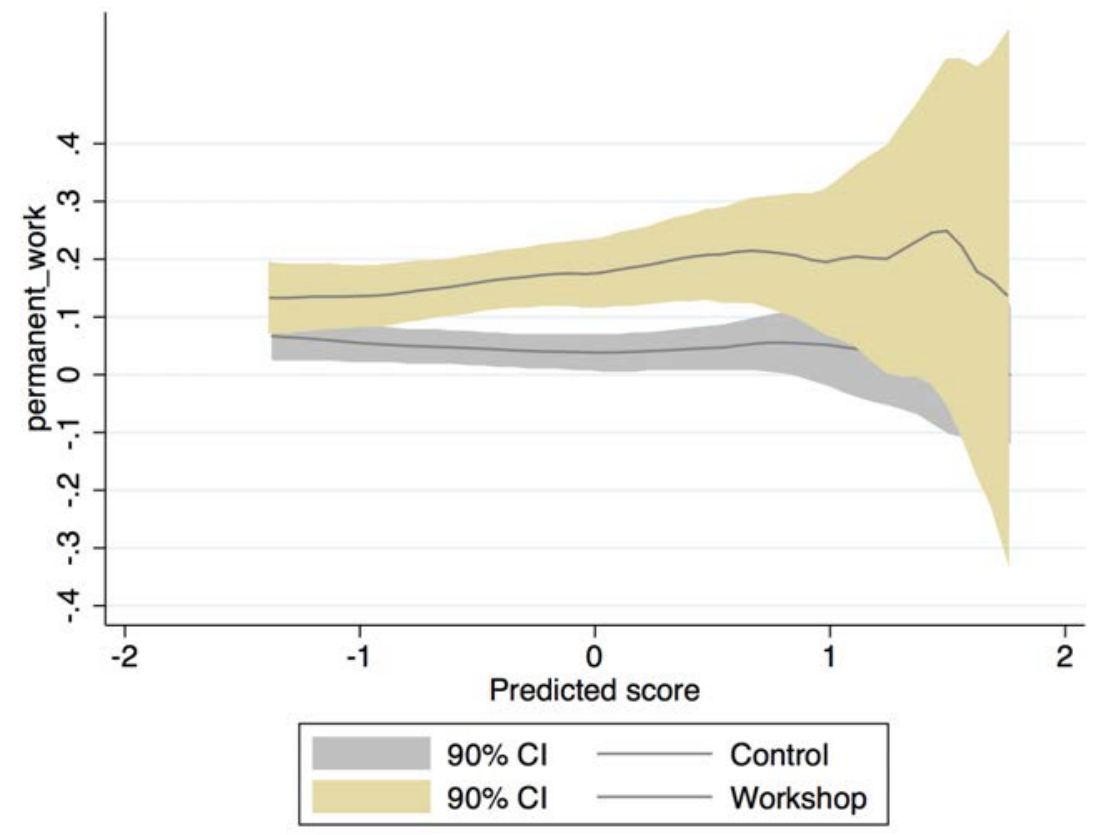


Figure 16: Impact of aggregate test scores on permanent work: Scoring above the median

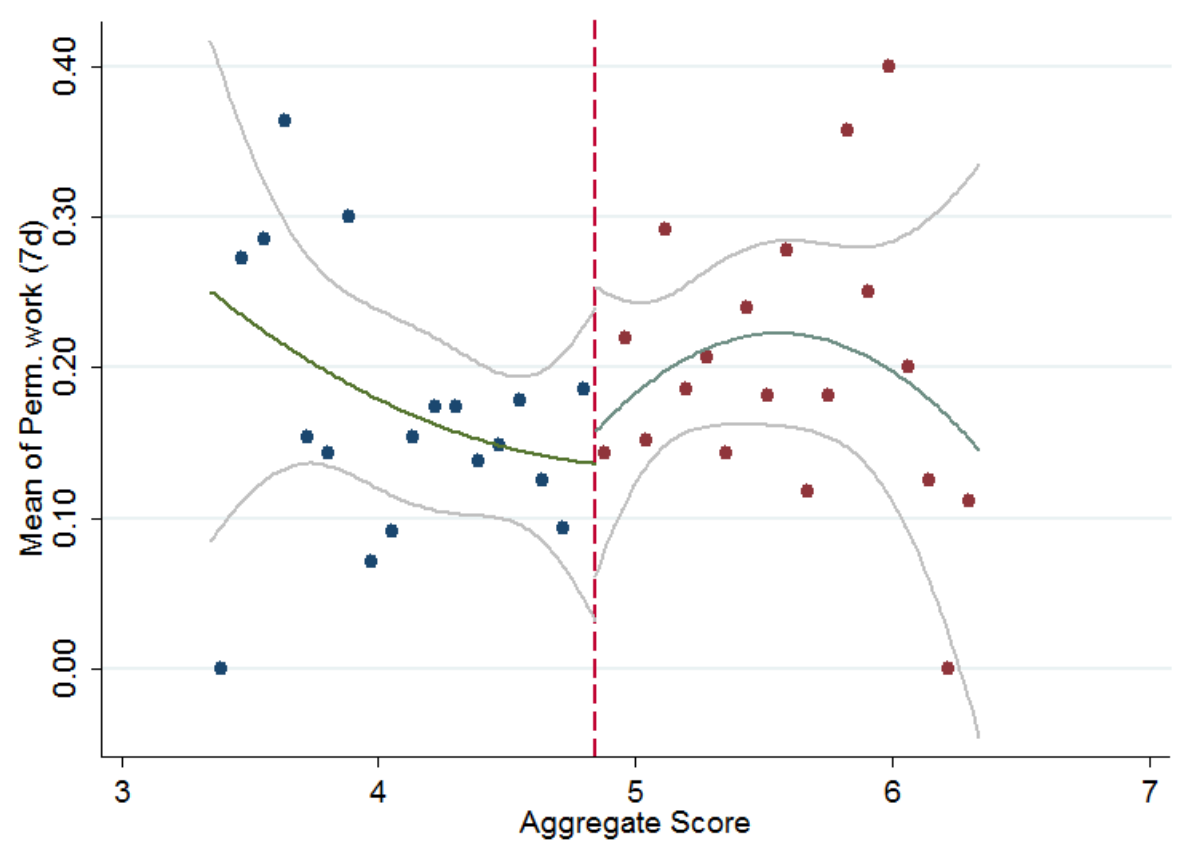


Figure 17: Relationship between distance and self-employment: Impact of transport subsidies

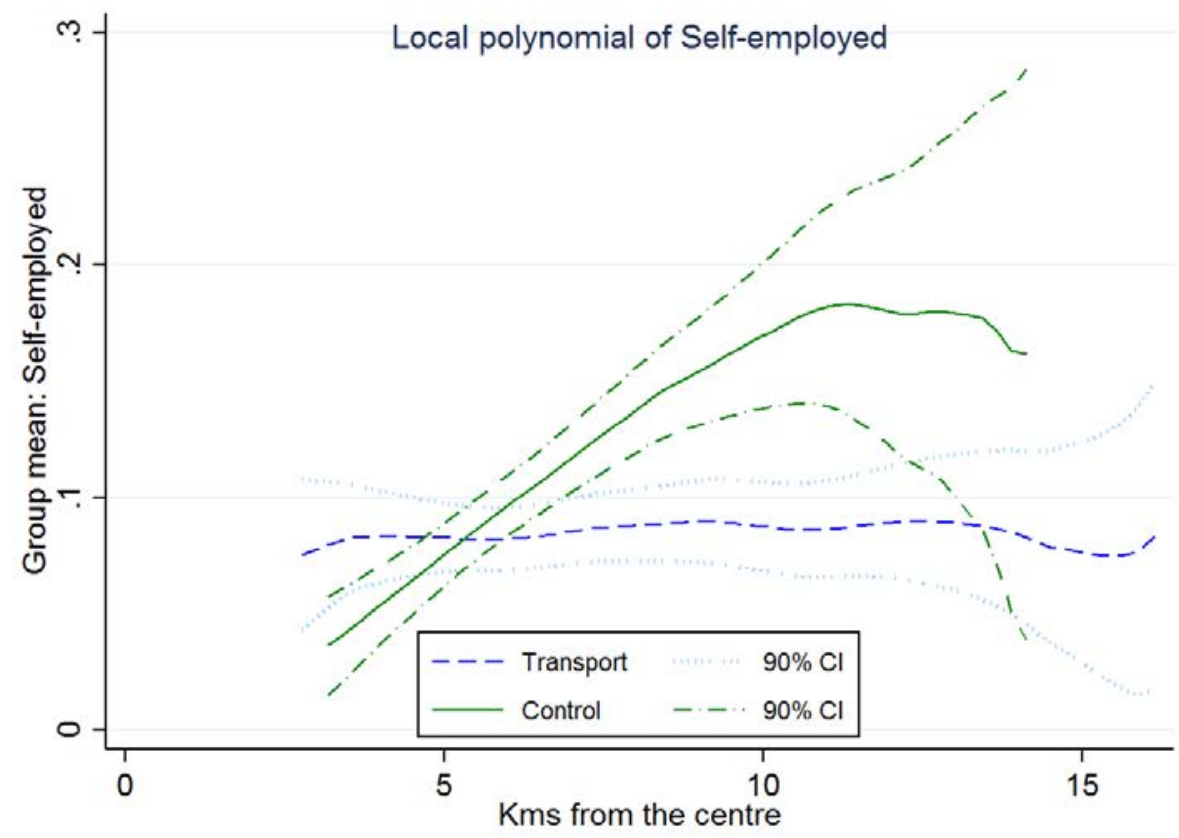


Figure 18: Relationship between distance and self-employment: Impact of the job application workshop

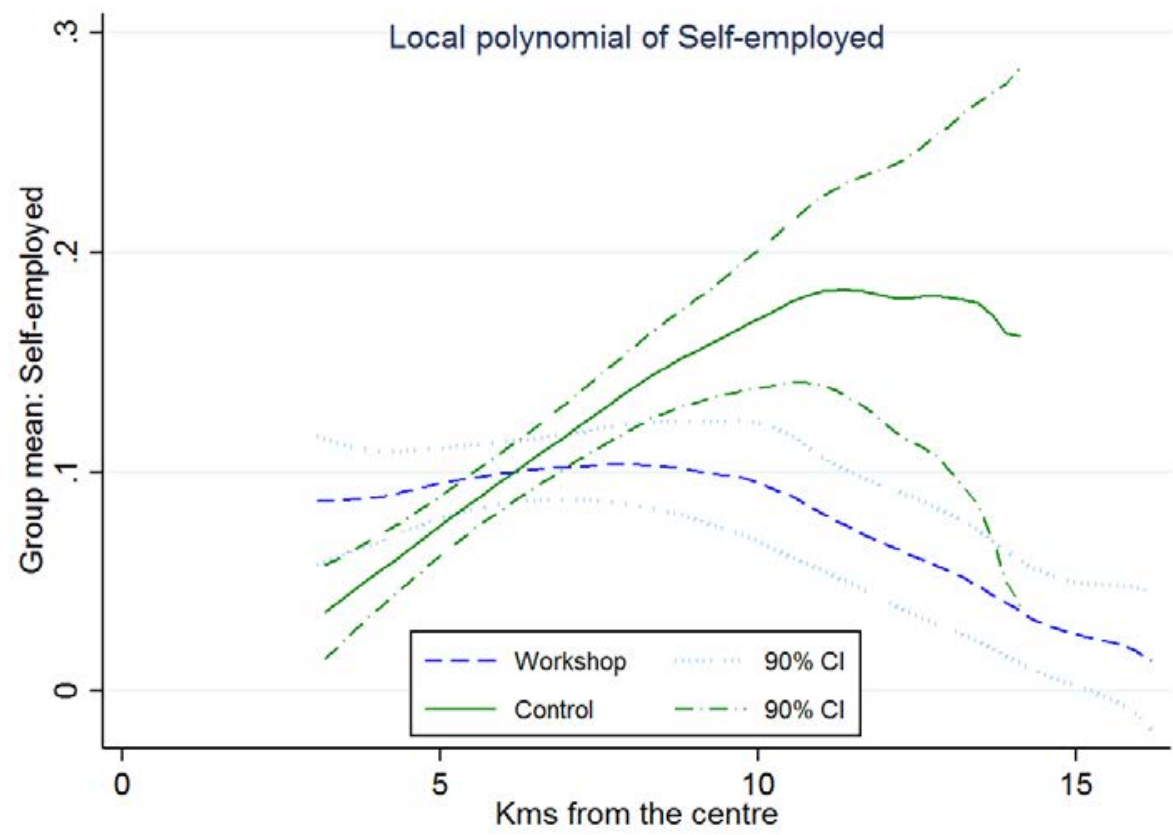


Table 1: Final Assignment to Treatment for Individuals and Clusters

\begin{tabular}{l|ccc||c}
\hline & $(1)$ & $(2)$ & $(3)$ & $(4)$ \\
Cluster Treatment & \multicolumn{3}{|c||}{ Individuals } & Clusters \\
& Control & Treated & Total & Total \\
\hline Transport & 500 & 774 & 1,274 & 74 \\
Workshop & 187 & 768 & 955 & 56 \\
Job fairs & 0 & 1007 & 1007 & 56 \\
Control & 823 & 0 & 823 & 48 \\
\hline & 1,510 & 2,549 & 4,059 & 234 \\
\hline
\end{tabular}

Table 2: Randomised Saturation Levels for the Transport Treatment

\begin{tabular}{|c|c|c|c|c|}
\hline \multirow[b]{3}{*}{ Proportion Treated } & \multirow{2}{*}{\multicolumn{2}{|c|}{$\begin{array}{l}(1) \quad(2) \\
\text { Individuals }\end{array}$}} & \multicolumn{2}{|c|}{ (3) $\quad(4)$} \\
\hline & & & & usters \\
\hline & Controls & Treated & Count & Proportion \\
\hline $20 \%$ & 256 & 65 & 18 & $24.32 \%$ \\
\hline $40 \%$ & 150 & 96 & 15 & $20.27 \%$ \\
\hline $75 \%$ & 56 & 191 & 15 & $20.27 \%$ \\
\hline $90 \%$ & 38 & 422 & 26 & $35.14 \%$ \\
\hline
\end{tabular}


Table 3: Employment outcomes

\begin{tabular}{|c|c|c|c|c|c|c|c|}
\hline Outcome & Transport & Job App. Workshop & Spillover 1 & Spillover 2 & Control Mean & $\mathrm{F}$ & $\mathrm{N}$ \\
\hline Worked & $\begin{array}{l}0.0400 \\
(.168) \\
{[.305]}\end{array}$ & $\begin{array}{c}0.0200 \\
(.529) \\
{[1]}\end{array}$ & $\begin{array}{c}-0.0450 \\
(.183) \\
{[1]}\end{array}$ & $\begin{array}{c}0.0320 \\
(.538) \\
{[1]}\end{array}$ & 0.562 & 0.494 & 3785 \\
\hline Hours worked & $\begin{array}{c}0.197 \\
(.9) \\
{[.717]}\end{array}$ & $\begin{array}{c}-0.0920 \\
(.953) \\
{[1]}\end{array}$ & $\begin{array}{c}-2.318 \\
(.213) \\
{[1]}\end{array}$ & $\begin{array}{c}0.616 \\
(.809) \\
{[1]}\end{array}$ & 26.20 & 0.842 & 3778 \\
\hline Formal work & $\begin{array}{c}0.0550 \\
(.004)^{* * *} \\
{[.031]^{* *}}\end{array}$ & $\begin{array}{c}0.0520 \\
(.009)^{* * *} \\
{[.029]^{* *}}\end{array}$ & $\begin{array}{c}0.0140 \\
(.491) \\
{[1]}\end{array}$ & $\begin{array}{c}0.0600 \\
(.113) \\
{[1]}\end{array}$ & 0.224 & 0.888 & 3785 \\
\hline Perm. work & $\begin{array}{c}0.0340 \\
(.062)^{*} \\
{[.23]}\end{array}$ & $\begin{array}{c}0.0670 \\
(.001)^{* * * *} \\
{[.005]^{* * *}}\end{array}$ & $\begin{array}{c}0.00600 \\
(.737) \\
{[1]}\end{array}$ & $\begin{array}{c}0.0150 \\
(.566) \\
{[1]}\end{array}$ & 0.171 & 0.114 & 3785 \\
\hline Self-employed & $\begin{array}{c}-0.0200 \\
(.187) \\
{[.305]}\end{array}$ & $\begin{array}{c}-0.00500 \\
(.739) \\
{[1]}\end{array}$ & $\begin{array}{c}-0.0170 \\
(.363) \\
{[1]}\end{array}$ & $\begin{array}{c}-0.0180 \\
(.542) \\
{[1]}\end{array}$ & 0.0950 & 0.346 & 3785 \\
\hline Monthly earnings & $\begin{array}{l}2.401 \\
(.974) \\
{[.717]}\end{array}$ & $\begin{array}{c}60.03 \\
(.479) \\
{[1]}\end{array}$ & $\begin{array}{c}-43.01 \\
(.634) \\
{[1]}\end{array}$ & $\begin{array}{c}12.12 \\
(.907) \\
{[1]}\end{array}$ & 1145 & 0.444 & 3732 \\
\hline Satis. with work & $\begin{array}{c}0.00300 \\
(.919) \\
{[.717]}\end{array}$ & $\begin{array}{c}0.0250 \\
(.356) \\
{[1]}\end{array}$ & $\begin{array}{c}-0.0170 \\
(.483) \\
{[1]}\end{array}$ & $\begin{array}{c}0.0510 \\
(.284) \\
{[1]}\end{array}$ & 0.237 & 0.473 & 3785 \\
\hline
\end{tabular}

Note. In this table we report the intent-to-treat estimates of the direct and indirect effects of the transport intervention and the job application workshop on primary employment outcomes. These are obtained by least squares estimation of equation (1), weighting each observation by the inverse of the probability of being sampled. Below each coefficient estimate, we report a p-value in parenthesis and a q-value in brackets. We correct standard errors to allow for arbitrary correlation at the level of geographical clusters. q-values are obtained using the sharpened procedure of Benjamini et al. (2006). In the last three columns we report the mean outcome for the control group, the p-value from a F-test of the null hypothesis that transport subsidies and the job application workshop have the same effect, and the number of observations. ${ }^{* * *} \mathrm{p}<0.01,{ }^{* *} \mathrm{p}<0.05$, * $\mathrm{p}<0.1$. 
Table 4: Job search

\begin{tabular}{|c|c|c|c|c|c|c|c|}
\hline Outcome & Transport & Job App. Workshop & Spillover 1 & Spillover 2 & Control Mean & $\mathrm{F}$ & $\mathrm{N}$ \\
\hline Applied to temporary jobs & $\begin{array}{l}0.344 \\
(.199) \\
{[.963]}\end{array}$ & $\begin{array}{c}-0.0110 \\
(.956) \\
{[1]}\end{array}$ & $\begin{array}{c}0.0160 \\
(.949) \\
{[1]}\end{array}$ & $\begin{array}{c}-0.168 \\
(.481) \\
{[1]}\end{array}$ & 1.311 & 0.141 & 3769 \\
\hline Applied to permanent jobs & $\begin{array}{c}-0.0210 \\
(.936) \\
{[.963]}\end{array}$ & $\begin{array}{c}0.0490 \\
(.842) \\
{[1]}\end{array}$ & $\begin{array}{c}0.0600 \\
(.838) \\
{[1]}\end{array}$ & $\begin{array}{c}0.0260 \\
(.931) \\
{[1]}\end{array}$ & 2.279 & 0.720 & 3764 \\
\hline Interviews/Applications & $\begin{array}{c}-0.0360 \\
(.23) \\
{[.963]}\end{array}$ & $\begin{array}{c}-0.0370 \\
(.168) \\
{[.732]}\end{array}$ & $\begin{array}{c}0.0340 \\
(.472) \\
{[1]}\end{array}$ & $\begin{array}{c}-0.0140 \\
(.789) \\
{[1]}\end{array}$ & 0.354 & 0.957 & 2139 \\
\hline Offers/Applications & $\begin{array}{c}0.00400 \\
(.924) \\
{[.963]}\end{array}$ & $\begin{array}{c}0.00300 \\
(.95) \\
{[1]}\end{array}$ & $\begin{array}{c}-0.0150 \\
(.72) \\
{[1]}\end{array}$ & $\begin{array}{c}0.0730 \\
(.28) \\
{[1]}\end{array}$ & 0.248 & 0.971 & 2140 \\
\hline Interviews/Applications (Perm) & $\begin{array}{c}0.00800 \\
(.841) \\
{[.963]}\end{array}$ & $\begin{array}{c}0.0110 \\
(.766) \\
{[1]}\end{array}$ & $\begin{array}{c}0.00600 \\
(.885) \\
{[1]}\end{array}$ & $\begin{array}{c}-0.0210 \\
(.71) \\
{[1]}\end{array}$ & 0.327 & 0.929 & 1659 \\
\hline Offers / Applications (Perm) & $\begin{array}{l}0.0470 \\
(.215) \\
{[.963]}\end{array}$ & $\begin{array}{l}0.0470 \\
(.169) \\
{[.732]}\end{array}$ & $\begin{array}{c}0.00800 \\
(.821) \\
{[1]}\end{array}$ & $\begin{array}{c}0.0520 \\
(.305) \\
{[1]}\end{array}$ & 0.164 & 0.995 & 1658 \\
\hline Interviews/Applications (Temp) & $\begin{array}{c}-0.0750 \\
(.07)^{*} \\
{[.963]}\end{array}$ & $\begin{array}{c}-0.0630 \\
(.125) \\
{[.732]}\end{array}$ & $\begin{array}{c}0.0330 \\
(.666) \\
{[1]}\end{array}$ & $\begin{array}{c}-0.0220 \\
(.755) \\
{[1]}\end{array}$ & 0.389 & 0.773 & 1314 \\
\hline Offers / Applications (Temp) & $\begin{array}{c}-0.0510 \\
(.245) \\
{[.963]}\end{array}$ & $\begin{array}{c}-0.0380 \\
(.401) \\
{[.732]}\end{array}$ & $\begin{array}{c}-0.0250 \\
(.658) \\
{[1]}\end{array}$ & $\begin{array}{c}0.109 \\
(.241) \\
{[1]}\end{array}$ & 0.332 & 0.756 & 1314 \\
\hline Uses CV for applications & $\begin{array}{l}0.0150 \\
(.604) \\
{[.963]}\end{array}$ & $\begin{array}{l}0.0420 \\
(.155) \\
{[.732]}\end{array}$ & $\begin{array}{c}0.0190 \\
(.576) \\
{[1]}\end{array}$ & $\begin{array}{c}-0.00500 \\
(.914) \\
{[1]}\end{array}$ & 0.401 & 0.313 & 3785 \\
\hline Uses certificates & $\begin{array}{c}0.0340 \\
(.4) \\
{[.963]}\end{array}$ & $\begin{array}{l}0.0520 \\
(.257) \\
{[.732]}\end{array}$ & $\begin{array}{c}0.0240 \\
(.561) \\
{[1]}\end{array}$ & $\begin{array}{c}0.0280 \\
(.619) \\
{[1]}\end{array}$ & 0.479 & 0.677 & 3785 \\
\hline
\end{tabular}

Note. In this table we report the intent-to-treat estimates of the direct and indirect effects of the transport intervention and the job application workshop on job search outcomes. These are obtained by least squares estimation of equation (1), weighting each observation by the inverse of the probability of being sampled. Below each coefficient estimate, we report a p-value in parenthesis and a q-value in brackets. We correct standard errors to allow for arbitrary correlation at the level of geographical clusters. q-values are obtained using the sharpened procedure of Benjamini et al. (2006). In the last three columns we report the mean outcome for the control group, the p-value from a F-test of the null hypothesis that transport subsidies and the job application workshop have the same effect, and the number of observations. ${ }^{* * *} \mathrm{p}<0.01,{ }^{* *} \mathrm{p}<0.05,{ }^{*} \mathrm{p}<0.1$. 
Table 5: Effects on main outcomes by gender

\begin{tabular}{|c|c|c|c|c|c|c|c|c|}
\hline \multirow[b]{2}{*}{ Outcome } & \multicolumn{3}{|c|}{ Transport } & \multicolumn{3}{|c|}{ Job Application Workshop } & \multicolumn{2}{|c|}{ Control Mean } \\
\hline & Male & Female & $F(p)$ & Male & Female & $F(p)$ & Male & Female \\
\hline Worked & $\begin{array}{l}0.0610 \\
(.138) \\
{[.709]}\end{array}$ & $\begin{array}{c}0.0210 \\
(.612) \\
{[1]}\end{array}$ & 0.502 & $\begin{array}{c}0.00100 \\
(.986) \\
{[1]}\end{array}$ & $\begin{array}{c}0.0370 \\
(.379) \\
{[1]}\end{array}$ & 0.529 & 0.642 & 0.487 \\
\hline Hours worked & $\begin{array}{c}0.118 \\
(.958) \\
{[1]}\end{array}$ & $\begin{array}{c}0.356 \\
(.872) \\
{[1]}\end{array}$ & 0.943 & $\begin{array}{c}-0.283 \\
(.891) \\
{[1]}\end{array}$ & $\begin{array}{c}0.486 \\
(.836) \\
{[1]}\end{array}$ & 0.815 & 28.80 & 23.80 \\
\hline Formal work & $\begin{array}{l}0.0490 \\
(.099)^{*} \\
{[.651]}\end{array}$ & $\begin{array}{l}0.0670 \\
(.013)^{* *} \\
{[.094]^{*}}\end{array}$ & 0.660 & $\begin{array}{c}0.00700 \\
(.827) \\
{[1]}\end{array}$ & $\begin{array}{c}0.0880 \\
(.001)^{* * *} \\
{[.016]^{* *}}\end{array}$ & 0.0476 & 0.246 & 0.203 \\
\hline Perm. work & $\begin{array}{c}-0.00300 \\
(.909) \\
{[1]}\end{array}$ & $\begin{array}{c}0.0660 \\
(.003)^{* * *} \\
{[.039]^{* *}}\end{array}$ & 0.0413 & $\begin{array}{c}0.0620 \\
(.032)^{* *} \\
{[.149]}\end{array}$ & $\begin{array}{l}0.0650 \\
(.011)^{* *} \\
{[.079]^{*}}\end{array}$ & 0.938 & 0.189 & 0.154 \\
\hline Self-employed & $\begin{array}{c}-0.0290 \\
(.305) \\
{[1]}\end{array}$ & $\begin{array}{c}-0.0190 \\
(.326) \\
{[1]}\end{array}$ & 0.786 & $\begin{array}{c}-0.00200 \\
(.942) \\
{[1]}\end{array}$ & $\begin{array}{c}-0.00600 \\
(.765) \\
{[1]}\end{array}$ & 0.910 & 0.109 & 0.0821 \\
\hline Monthly earnings & $\begin{array}{c}-3.308 \\
(.981) \\
{[1]}\end{array}$ & $\begin{array}{c}17.48 \\
(.807) \\
{[1]}\end{array}$ & 0.894 & $\begin{array}{c}102.3 \\
(.495) \\
{[1]}\end{array}$ & $\begin{array}{c}63.11 \\
(.47) \\
{[1]}\end{array}$ & 0.818 & 1521 & 794 \\
\hline Satis. with work & $\begin{array}{c}-0.0230 \\
(.569) \\
{[1]}\end{array}$ & $\begin{array}{c}0.0210 \\
(.547) \\
{[1]}\end{array}$ & 0.390 & $\begin{array}{c}0.0220 \\
(.598) \\
{[1]}\end{array}$ & $\begin{array}{c}0.0290 \\
(.404) \\
{[1]}\end{array}$ & 0.899 & 0.287 & 0.190 \\
\hline
\end{tabular}

Note. In this table we report, separately for each gender, the intent-to-treat estimates of the direct effects of the transport intervention and the job application workshop on primary employment outcomes. These are obtained by least squares estimation of equation (2), weighting each observation by the inverse of the probability of being sampled. Below each coefficient estimate, we report a p-value in parenthesis and a q-value in brackets. We correct standard errors to allow for arbitrary correlation at the level of geographical clusters. q-values are obtained using the sharpened procedure of Benjamini et al. (2006). In columns 3 and 6 we report the p-value from F-tests of the null hypotheses that transport subsidies and the job application workshop, respectively, have the same effect for men and women. In the last two columns we report the mean outcome for men and women in the control group. ${ }^{* *} \mathrm{p}<0.01,{ }^{* *} \mathrm{p}<0.05,{ }^{*} \mathrm{p}<0.1$. 
Table 6: Effects on main outcomes by education

\begin{tabular}{|c|c|c|c|c|c|c|c|c|c|c|c|}
\hline \multirow[b]{2}{*}{ Outcome } & \multicolumn{4}{|c|}{ Transport } & \multicolumn{4}{|c|}{ Job Application Workshop } & \multicolumn{3}{|c|}{ Control Mean } \\
\hline & High Sch. & Vocat. & Dip/Deg & $F(p)$ & High Sch. & Vocat. & Dip/Deg & $F(p)$ & High Sch. & Vocat. & Dip/Deg \\
\hline Worked & $\begin{array}{c}0.0540 \\
(.219) \\
{[1]}\end{array}$ & $\begin{array}{c}0.0270 \\
(.458) \\
{[1]}\end{array}$ & $\begin{array}{c}-0.0220 \\
(.648) \\
{[1]}\end{array}$ & 0.534 & $\begin{array}{c}-0.00400 \\
(.929) \\
{[1]}\end{array}$ & $\begin{array}{c}0.0750 \\
(.023)^{* *} \\
{[.177]}\end{array}$ & $\begin{array}{c}-0.0140 \\
(.787) \\
{[1]}\end{array}$ & 0.153 & 0.508 & 0.546 & 0.694 \\
\hline Hours worked & $\begin{array}{c}0.690 \\
(.767) \\
{[1]}\end{array}$ & $\begin{array}{c}-0.343 \\
(.848) \\
{[1]}\end{array}$ & $\begin{array}{c}-0.907 \\
(.731) \\
{[1]}\end{array}$ & 0.897 & $\begin{array}{c}-1.744 \\
(.446) \\
{[1]}\end{array}$ & $\begin{array}{l}2.935 \\
(.081)^{*} \\
{[.571]}\end{array}$ & $\begin{array}{c}2.402 \\
(.379) \\
{[1]}\end{array}$ & 0.233 & 24.80 & 26 & 29 \\
\hline Formal work & $\begin{array}{l}0.0750 \\
(.01)^{* * * *} \\
{[.121]}\end{array}$ & $\begin{array}{c}0.0250 \\
(.429) \\
{[1]}\end{array}$ & $\begin{array}{c}0.0740 \\
(.186) \\
{[1]}\end{array}$ & 0.504 & $\begin{array}{c}0.0680 \\
(.019)^{* *} \\
{[.177]}\end{array}$ & $\begin{array}{c}0.0450 \\
(.13) \\
{[.736]}\end{array}$ & $\begin{array}{c}-0.0430 \\
(.389) \\
{[1]}\end{array}$ & 0.150 & 0.108 & 0.228 & 0.403 \\
\hline Perm. work & $\begin{array}{c}0.0650 \\
(.008)^{* * *} \\
{[.121]}\end{array}$ & $\begin{array}{c}-0.00700 \\
(.805) \\
{[1]}\end{array}$ & $\begin{array}{c}-0.0210 \\
(.72) \\
{[1]}\end{array}$ & 0.0997 & $\begin{array}{c}0.102 \\
(0)^{* * *} \\
{[.007]^{* * *}}\end{array}$ & $\begin{array}{c}0.0170 \\
(.48) \\
{[1]}\end{array}$ & $\begin{array}{c}-0.0200 \\
(.73) \\
{[1]}\end{array}$ & 0.0414 & 0.0583 & 0.172 & 0.354 \\
\hline Self-employed & $\begin{array}{c}-0.0370 \\
(.144) \\
{[1]}\end{array}$ & $\begin{array}{c}0 \\
(.994) \\
{[1]}\end{array}$ & $\begin{array}{c}-0.0250 \\
(.521) \\
{[1]}\end{array}$ & 0.529 & $\begin{array}{c}-0.0300 \\
(.196) \\
{[.736]}\end{array}$ & $\begin{array}{l}0.0260 \\
(.215) \\
{[.736]}\end{array}$ & $\begin{array}{l}0.0600 \\
(.155) \\
{[.736]}\end{array}$ & 0.0939 & 0.112 & 0.0780 & 0.111 \\
\hline Monthly earnings & $\begin{array}{c}99.64 \\
(.32) \\
{[1]}\end{array}$ & $\begin{array}{c}-134.0 \\
(.136) \\
{[1]}\end{array}$ & $\begin{array}{c}-121.1 \\
(.724) \\
{[1]}\end{array}$ & 0.197 & $\begin{array}{c}101.0 \\
(.377) \\
{[1]}\end{array}$ & $\begin{array}{l}121.3 \\
(.285) \\
{[.941]}\end{array}$ & $\begin{array}{c}-202.2 \\
(.58) \\
{[1]}\end{array}$ & 0.699 & 780 & 1023 & 2072 \\
\hline Satis. with work & $\begin{array}{c}0.0120 \\
(.73) \\
{[1]}\end{array}$ & $\begin{array}{c}-0.0210 \\
(.56) \\
{[1]}\end{array}$ & $\begin{array}{c}0 \\
(.998) \\
{[1]}\end{array}$ & 0.746 & $\begin{array}{c}0.0130 \\
(.707) \\
{[1]}\end{array}$ & $\begin{array}{l}0.0470 \\
(.196) \\
{[.736]}\end{array}$ & $\begin{array}{c}0.0340 \\
(.567) \\
{[1]}\end{array}$ & 0.760 & 0.225 & 0.234 & 0.264 \\
\hline
\end{tabular}

Note. In this table we report, separately for each education category, the intent-to-treat estimates of the direct of the transport intervention and the job application workshop on primary employment outcomes. These are obtained by least squares estimation of equation (2). Below each coefficient estimate, we report a p-value in parenthesis and a q-value in brackets. We correct standard errors to allow for arbitrary correlation at the level of geographical clusters. q-values are obtained using the sharpened procedure of Benjamini et al. (2006). In columns 3 and 6 we report the p-value from F-tests of the null hypotheses that transport subsidies and the job application workshop, respectively, have the same effect for individuals with different levels of education. In the last three columns we report the mean outcome in the control group for the different education categories. ${ }^{* *} \mathrm{p}<0.01,{ }^{* *} \mathrm{p}<0.05,{ }^{*} \mathrm{p}<0.1$. 
Table 7: Effects on search outcomes by education

\begin{tabular}{|c|c|c|c|c|c|c|c|c|c|c|c|}
\hline \multirow[b]{2}{*}{ Outcome } & \multicolumn{4}{|c|}{ Transport } & \multicolumn{4}{|c|}{ Job Application Workshop } & \multicolumn{3}{|c|}{ Control Mean } \\
\hline & High Sch. & Vocat. & Dip/Deg & $F(p)$ & High Sch. & Vocat. & Dip/Deg & $F(p)$ & High Sch. & Vocat. & Dip/Deg \\
\hline Applied to temporary jobs & $\begin{array}{c}0.471 \\
(.142) \\
{[1]}\end{array}$ & $\begin{array}{c}0.118 \\
(.693) \\
{[1]}\end{array}$ & $\begin{array}{c}0.242 \\
(.736) \\
{[1]}\end{array}$ & 0.631 & $\begin{array}{c}-0.00800 \\
(.974) \\
{[1]}\end{array}$ & $\begin{array}{c}0.0230 \\
(.926) \\
{[1]}\end{array}$ & $\begin{array}{c}-0.115 \\
(.868) \\
{[1]}\end{array}$ & 0.973 & 0.887 & 1.420 & 1.740 \\
\hline Applied to permanent jobs & $\begin{array}{c}-0.170 \\
(.356) \\
{[1]}\end{array}$ & $\begin{array}{c}0.210 \\
(.549) \\
{[1]}\end{array}$ & $\begin{array}{c}0.402 \\
(.688) \\
{[1]}\end{array}$ & 0.385 & $\begin{array}{c}0.136 \\
(.528) \\
{[1]}\end{array}$ & $\begin{array}{c}0.0890 \\
(.767) \\
{[1]}\end{array}$ & $\begin{array}{c}-0.339 \\
(.721) \\
{[1]}\end{array}$ & 0.872 & 0.854 & 2 & 5.380 \\
\hline Interviews/Applications & $\begin{array}{c}-0.0540 \\
(.283) \\
{[1]}\end{array}$ & $\begin{array}{c}-0.0190 \\
(.586) \\
{[1]}\end{array}$ & $\begin{array}{c}-0.0470 \\
(.236) \\
{[1]}\end{array}$ & 0.765 & $\begin{array}{c}-0.0890 \\
(.046)^{* *} \\
{[.552]}\end{array}$ & $\begin{array}{c}0.0200 \\
(.581) \\
{[1]}\end{array}$ & $\begin{array}{c}-0.0270 \\
(.56) \\
{[1]}\end{array}$ & 0.168 & 0.337 & 0.371 & 0.337 \\
\hline Offers/Applications & $\begin{array}{c}0.0580 \\
(.328) \\
{[1]}\end{array}$ & $\begin{array}{c}-0.0510 \\
(.236) \\
{[1]}\end{array}$ & $\begin{array}{c}-0.0250 \\
(.57) \\
{[1]}\end{array}$ & 0.259 & $\begin{array}{c}0.00300 \\
(.954) \\
{[1]}\end{array}$ & $\begin{array}{c}-0.0130 \\
(.791) \\
{[1]}\end{array}$ & $\begin{array}{c}-0.00100 \\
(.985) \\
{[1]}\end{array}$ & 0.961 & 0.263 & 0.279 & 0.161 \\
\hline Interviews/Applications (Perm) & $\begin{array}{c}0.00200 \\
(.978) \\
{[1]}\end{array}$ & $\begin{array}{c}-0.0190 \\
(.662) \\
{[1]}\end{array}$ & $\begin{array}{c}-0.0380 \\
(.388) \\
{[1]}\end{array}$ & 0.878 & $\begin{array}{c}-0.00300 \\
(.966) \\
{[1]}\end{array}$ & $\begin{array}{c}0.0170 \\
(.702) \\
{[1]}\end{array}$ & $\begin{array}{c}-0.0160 \\
(.723) \\
{[1]}\end{array}$ & 0.868 & 0.287 & 0.352 & 0.312 \\
\hline Offers/Applications (Perm) & $\begin{array}{c}0.108 \\
(.085)^{*} \\
{[1]}\end{array}$ & $\begin{array}{c}-0.0130 \\
(.768) \\
{[1]}\end{array}$ & $\begin{array}{c}-0.0590 \\
(.172) \\
{[1]}\end{array}$ & 0.0878 & $\begin{array}{c}0.110 \\
(.014)^{* *} \\
{[.552]}\end{array}$ & $\begin{array}{c}-0.0180 \\
(.715) \\
{[1]}\end{array}$ & $\begin{array}{c}-0.0340 \\
(.414) \\
{[1]}\end{array}$ & 0.0359 & 0.0957 & 0.202 & 0.143 \\
\hline Interviews/Applications (Temp) & $\begin{array}{c}-0.0880 \\
(.181) \\
{[1]}\end{array}$ & $\begin{array}{c}-0.00600 \\
(.905) \\
{[1]}\end{array}$ & $\begin{array}{c}-0.134 \\
(.045)^{* *} \\
{[1]}\end{array}$ & 0.244 & $\begin{array}{c}-0.136 \\
(.024)^{* *} \\
{[.552]}\end{array}$ & $\begin{array}{c}0.0170 \\
(.726) \\
{[1]}\end{array}$ & $\begin{array}{c}-0.0230 \\
(.775) \\
{[1]}\end{array}$ & 0.120 & 0.375 & 0.394 & 0.398 \\
\hline Offers/Applications (Temp) & $\begin{array}{c}-0.0300 \\
(.672) \\
{[1]}\end{array}$ & $\begin{array}{c}-0.0490 \\
(.278) \\
{[1]}\end{array}$ & $\begin{array}{c}0 \\
(.996) \\
{[1]}\end{array}$ & 0.840 & $\begin{array}{c}-0.0900 \\
(.251) \\
{[1]}\end{array}$ & $\begin{array}{c}0.00100 \\
(.991) \\
{[1]}\end{array}$ & $\begin{array}{c}0.0340 \\
(.676) \\
{[1]}\end{array}$ & 0.552 & 0.362 & 0.346 & 0.241 \\
\hline Uses CV for applications & $\begin{array}{c}-0.0270 \\
(.481) \\
{[1]}\end{array}$ & $\begin{array}{c}0.0880 \\
(.016)^{* *} \\
{[.97]}\end{array}$ & $\begin{array}{c}0.0520 \\
(.32) \\
{[1]}\end{array}$ & 0.0281 & $\begin{array}{c}0.0290 \\
(.488) \\
{[1]}\end{array}$ & $\begin{array}{c}0.0720 \\
(.049)^{* *} \\
{[.552]}\end{array}$ & $\begin{array}{c}0.0380 \\
(.471) \\
{[1]}\end{array}$ & 0.673 & 0.192 & 0.406 & 0.736 \\
\hline Uses certificates & $\begin{array}{c}-0.0150 \\
(.739) \\
{[1]}\end{array}$ & $\begin{array}{c}0.0900 \\
(.059)^{*} \\
{[1]}\end{array}$ & $\begin{array}{c}0.0720 \\
(.243) \\
{[1]}\end{array}$ & 0.163 & $\begin{array}{c}0.0650 \\
(.27) \\
{[1]}\end{array}$ & $\begin{array}{c}0.0100 \\
(.845) \\
{[1]}\end{array}$ & $\begin{array}{c}0.0870 \\
(.173) \\
{[1]}\end{array}$ & 0.421 & 0.296 & 0.538 & 0.632 \\
\hline
\end{tabular}

Note. In this table we report, separately for each education category, the intent-to-treat estimates of the direct effects of the transport intervention and the job application workshop on job search outcomes. These are obtained by least squares estimation of equation (2). Below each coefficient estimate, we report a p-value in parenthesis and a q-value in brackets. We correct standard errors to allow for arbitrary correlation at the level of geographical clusters. q-values are obtained using the sharpened procedure of Benjamini et al. (2006). In columns 3 and 6 we report the p-value from F-tests of the null hypotheses that transport subsidies and the job application workshop, respectively, have the same effect for individuals with different levels of education. In the last three columns we report the mean outcome in the control group for the different education categories. ${ }^{* * *} \mathrm{p}<0.01,{ }^{* *} \mathrm{p}<0.05,{ }^{*} \mathrm{p}<0.1$. 


\section{Online Appendix}




\section{Appendix A: Further details}

Figure 19: Attrition (failure to complete one phone interview) from the Phone Survey by Month

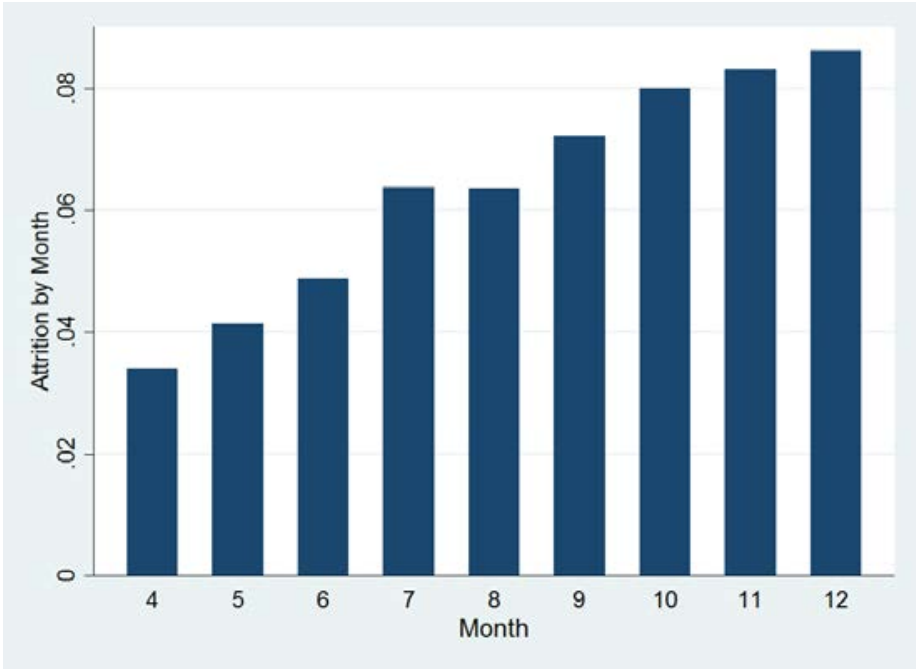

Table 8: Sample selection before randomisation

\begin{tabular}{lccc}
\hline & Sample Size & No. Dropped & $\%$ dropped \\
\hline Eligible at baseline & 4388 & & \\
Found on phone & 4314 & 74 & $1.69 \%$ \\
Stayed in phone survey & 4254 & 60 & $1.39 \%$ \\
Without permanent work & 4076 & 178 & $4.18 \%$ \\
Stayed in Addis & 4059 & 17 & $0.42 \%$ \\
& & & \\
\hline Total Dropped & & 329 & $7.58 \%$ \\
Final Sample & 4059 & & \\
\hline
\end{tabular}

Table 10: Summary and Tests of Balance

\begin{tabular}{|c|c|c|c|c|c|c|c|c|c|}
\hline & $\mathrm{N}$ & Mean & S.Dev. & 1st Q. & Median & 3rd Q. & Min. & Max. & F-test $\mathrm{P}$ \\
\hline degree & 4055 & 0.18 & 0.39 & 0.00 & 0.00 & 0.00 & 0.0 & 1.0 & 0.654 \\
\hline vocational & 4055 & 0.43 & 0.50 & 0.00 & 0.00 & 1.00 & 0.0 & 1.0 & 0.914 \\
\hline work & 4055 & 0.30 & 0.46 & 0.00 & 0.00 & 1.00 & 0.0 & 1.0 & 0.710 \\
\hline search & 4055 & 0.50 & 0.50 & 0.00 & 0.00 & 1.00 & 0.0 & 1.0 & 0.950 \\
\hline dipdeg & 4055 & 0.25 & 0.43 & 0.00 & 0.00 & 1.00 & 0.0 & 1.0 & 0.933 \\
\hline female & 4055 & 0.53 & 0.50 & 0.00 & 1.00 & 1.00 & 0.0 & 1.0 & 0.996 \\
\hline migrant_birth & 4055 & 0.36 & 0.48 & 0.00 & 0.00 & 1.00 & 0.0 & 1.0 & 0.684 \\
\hline amhara & 4055 & 0.44 & 0.50 & 0.00 & 0.00 & 1.00 & 0.0 & 1.0 & 0.366 \\
\hline oromo & 4055 & 0.25 & 0.44 & 0.00 & 0.00 & 1.00 & 0.0 & 1.0 & 0.278 \\
\hline work_wage_6months & 4055 & 0.45 & 0.50 & 0.00 & 0.00 & 1.00 & 0.0 & 1.0 & 0.452 \\
\hline
\end{tabular}




\begin{tabular}{|c|c|c|c|c|c|c|c|c|c|}
\hline married & 4055 & 0.20 & 0.40 & 0.00 & 0.00 & 0.00 & 0.0 & 1.0 & 0.462 \\
\hline live_parents & 4055 & 0.53 & 0.50 & 0.00 & 1.00 & 1.00 & 0.0 & 1.0 & 0.779 \\
\hline experience_perm & 4055 & 0.13 & 0.33 & 0.00 & 0.00 & 0.00 & 0.0 & 1.0 & 0.430 \\
\hline search_6months & 4055 & 0.75 & 0.43 & 0.00 & 1.00 & 1.00 & 0.0 & 1.0 & 0.565 \\
\hline respondent_age & 4055 & 23.53 & 3.00 & 21.00 & 23.00 & 26.00 & 18.0 & 29.0 & 0.678 \\
\hline years_since_school & 4050 & 38.35 & 259.95 & 1.00 & 3.00 & 5.00 & 0.0 & 1984.0 & 0.316 \\
\hline search_freq & 4055 & 0.57 & 0.32 & 0.33 & 0.60 & 0.83 & 0.0 & 1.0 & 0.760 \\
\hline work_freq & 4055 & 0.34 & 0.38 & 0.00 & 0.20 & 0.67 & 0.0 & 1.0 & 0.823 \\
\hline self_employed & 4055 & 0.05 & 0.22 & 0.00 & 0.00 & 0.00 & 0.0 & 1.0 & 0.539 \\
\hline work_cas & 4055 & 0.05 & 0.21 & 0.00 & 0.00 & 0.00 & 0.0 & 1.0 & 0.291 \\
\hline work_satisfaction & 4055 & 0.09 & 0.28 & 0.00 & 0.00 & 0.00 & 0.0 & 1.0 & 0.496 \\
\hline total_savings & 4055 & 2441.42 & 7232.39 & 0.00 & 0.00 & 2200.00 & 0.0 & 202998.0 & 0.320 \\
\hline res_wage & 4014 & 1361.68 & 1072.74 & 800.00 & 1100.00 & 1700.00 & 0.0 & 20000.0 & 0.786 \\
\hline cent_dist & 4055 & 5.91 & 2.57 & 3.76 & 5.31 & 7.57 & 2.5 & 12.7 & 0.269 \\
\hline travel & 4050 & 1.90 & 2.10 & 0.00 & 1.00 & 3.00 & 0.0 & 18.0 & 0.391 \\
\hline written_agreement & 4055 & 0.07 & 0.26 & 0.00 & 0.00 & 0.00 & 0.0 & 1.0 & 0.311 \\
\hline cv_application & 4055 & 0.28 & 0.45 & 0.00 & 0.00 & 1.00 & 0.0 & 1.0 & 0.701 \\
\hline expect_offer & 3812 & 1.44 & 2.13 & 0.00 & 1.00 & 2.00 & 0.0 & 60.0 & 0.084 \\
\hline aspiration & 3803 & 5820.25 & 5778.53 & 3000.00 & 5000.00 & 6000.00 & 0.0 & 99999.0 & 0.793 \\
\hline network_size & 4016 & 6.79 & 9.44 & 3.00 & 4.00 & 8.00 & 0.0 & 99.0 & 0.561 \\
\hline respondent_age & 4055 & 23.53 & 3.00 & 21.00 & 23.00 & 26.00 & 18.0 & 29.0 & 0.678 \\
\hline present_bias & 2768 & 0.13 & 0.34 & 0.00 & 0.00 & 0.00 & 0.0 & 1.0 & 0.563 \\
\hline future_bias & 2768 & 0.07 & 0.25 & 0.00 & 0.00 & 0.00 & 0.0 & 1.0 & 0.186 \\
\hline life_satisfaction & 4051 & 4.16 & 1.87 & 3.00 & 4.00 & 5.00 & 0.0 & 10.0 & 0.944 \\
\hline
\end{tabular}

Table 12: Variables Used for Re-Randomisation

\begin{tabular}{|c|c|c|}
\hline VARIABLE & DEFINITION & SOURCE (QUESTION NUMBER) \\
\hline degree & $\begin{array}{l}\text { Dummy: Individual has finished a degree (bachelors or } \\
\text { above) at a recognised university }\end{array}$ & Dummy: b5=20 or b5=21 \\
\hline vocational & $\begin{array}{l}\text { Dummy: Individual has finished a course or vocational } \\
\text { training at an official vocational college or TVET }\end{array}$ & Dummy: b5 $\in\{9, \ldots, 16\}$ \\
\hline work & Individual has had any work for pay in the last 7 days & Dummy: j1_1 = 1 \\
\hline search & $\begin{array}{l}\text { Individual has taken any active step to find work in the } \\
\text { last } 7 \text { days }\end{array}$ & Dummy: s0_2 = 1 \\
\hline post_secondary & $\begin{array}{l}\text { Individual has any kind of non-vocational post- } \\
\text { secondary education (degree or diploma) }\end{array}$ & Dummy: b5 $\in\{17, \ldots, 21\}$. \\
\hline female & Respondent is female & $\begin{array}{ll}\text { Dummy: } & \text { respon- } \\
\text { dent_gender }=2\end{array}$ \\
\hline migrant_birth & $\begin{array}{l}\text { Respondent was born outside of Addis Ababa and mi- } \\
\text { grated since birth }\end{array}$ & Dummy: b14!=10 \\
\hline amhara & Respondent is ethnically Amhara & Dummy: b21=1 \\
\hline oromo & Respondent is ethnically Oromo & Dummy: b21=2 \\
\hline work_wage_6months & $\begin{array}{l}\text { Individual has worked for a wage at any point in the last } \\
6 \text { months }\end{array}$ & Dummy: j2_1 =1 \\
\hline married & Individual is married & Dummy: b1 = 1 \\
\hline live_parents & Respondents lives with his/her mother or father & Dummy: b22 $=3$ or $b 22=4$ \\
\hline experience_perm & Respondent has work experience at a permanent job & Dummy: $b 22=3$ or $b 22=4$ \\
\hline search_6months & $\begin{array}{l}\text { Respondent has searched for work any time in the last } 6 \\
\text { months }\end{array}$ & Dummy: s0_1 = 1 \\
\hline
\end{tabular}




\begin{tabular}{l|l|l}
\hline age & Respondent age & respondent_age \\
\hline years_since_school & $\begin{array}{l}\text { Years since the respondent finished school (any school } \\
\text { including university) }\end{array}$ & $\begin{array}{l}\text { Constructed from j0_3 }(= \\
\left.2006-j 0 \_3\right)\end{array}$ \\
\hline search_freq & $\begin{array}{l}\text { Proportion of weeks that individual searched for work } \\
\text { (from the phone surveys) }\end{array}$ & $\begin{array}{l}\text { Mean (over first 3 months of } \\
\text { calls) of Dummy: } p 1 \_14=1\end{array}$ \\
\hline work_freq & $\begin{array}{l}\text { Proportion of weeks that the individuals worked (from } \\
\text { the phone surveys) }\end{array}$ & $\begin{array}{l}\text { Mean (over first 3 months of } \\
\text { calls) of Dummy: } p 1 \_3 \neq 0\end{array}$ \\
\hline
\end{tabular}


Table 9: Assignment to Start and End Weeks of the Transport Intervention

\begin{tabular}{l|cccccc|c} 
& \multicolumn{7}{c}{ End Week (2014-2015) } \\
\hline Start Week (2014) & 22-Dec & 29-Dec & 05-Jan & 12-Jan & 19-Jan & 26-Jan & Total \\
\hline 01-Sep & 12 & 11 & 14 & 13 & 0 & 0 & 50 \\
08-Sep & 12 & 21 & 38 & 29 & 0 & 0 & 100 \\
15-Sep & 6 & 10 & 12 & 22 & 0 & 0 & 50 \\
22-Sep & 10 & 15 & 27 & 24 & 0 & 0 & 76 \\
29-Sep & 16 & 23 & 29 & 78 & 25 & 29 & 200 \\
06-Oct & 0 & 0 & 0 & 53 & 51 & 46 & 150 \\
13-Oct & 0 & 0 & 0 & 59 & 44 & 45 & 148 \\
& & & & & & & \\
\hline Total & 56 & 80 & 120 & 278 & 120 & 120 & 774 \\
\hline
\end{tabular}

Figure 20: Heterogeneous Impacts by Education: Reservation wages

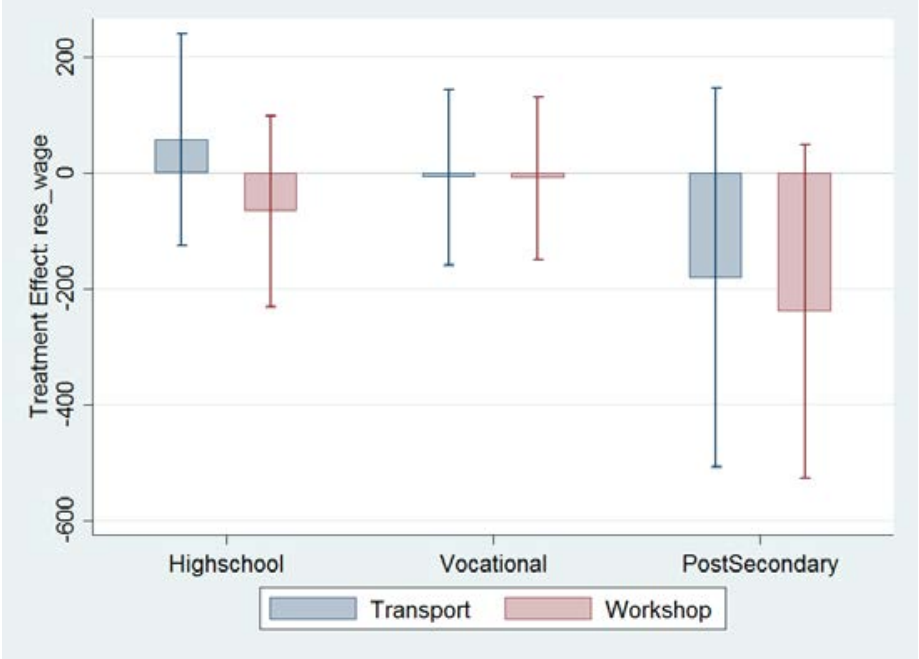


Table 11: Predictors of Attrition

\begin{tabular}{|c|c|c|c|}
\hline \multicolumn{4}{|c|}{$\begin{array}{c}(1) \\
\text { Attrition }\end{array}$} \\
\hline Transport & $\begin{array}{l}-0.005 \\
(0.017)\end{array}$ & Respondent age & $\begin{array}{c}-0.000 \\
(0.0022)\end{array}$ \\
\hline Screening & $\begin{array}{l}-0.023 \\
(0.017)\end{array}$ & Born outside Addis & $\begin{array}{c}0.040^{* * *} \\
(0.014)\end{array}$ \\
\hline Spillover transport & $\begin{array}{l}-0.010 \\
(0.019)\end{array}$ & Amhara & $\begin{array}{l}-0.024 \\
(0.015)\end{array}$ \\
\hline Spillover screening & $\begin{array}{l}-0.014 \\
(0.026)\end{array}$ & Oromo & $\begin{array}{l}-0.026 \\
(0.017)\end{array}$ \\
\hline search freq & $\begin{array}{c}-0.064^{* *} \\
(0.026)\end{array}$ & Wage empl (6m) & $\begin{array}{c}0.011 \\
(0.015)\end{array}$ \\
\hline work freq & $\begin{array}{c}-0.004 \\
(0.018)\end{array}$ & Married & $\begin{array}{l}-0.028 \\
(0.018)\end{array}$ \\
\hline Degree & $\begin{array}{c}-0.034^{* * *} \\
(0.012)\end{array}$ & Years since school & $\begin{array}{c}0.000 \\
(0.000029)\end{array}$ \\
\hline Worked (7d) & $\begin{array}{c}-0.044^{* * *} \\
(0.015)\end{array}$ & Lives with parents & $\begin{array}{c}-0.004 \\
(0.014)\end{array}$ \\
\hline Searched job $(7 d)$ & $\begin{array}{c}0.021 \\
(0.016)\end{array}$ & Ever had permanent job & $\begin{array}{c}0.003 \\
(0.018)\end{array}$ \\
\hline Female & $\begin{array}{l}0.022^{*} \\
(0.013)\end{array}$ & Searched job $(6 \mathrm{~m})$ & $\begin{array}{l}-0.007 \\
(0.018)\end{array}$ \\
\hline Observations & 3,045 & R-squared & 0.021 \\
\hline F-test (treatments) & 0.560 & F-test (covariates) & 2.680 \\
\hline Prob $>$ F & 0.690 & Prob $>$ F & 0.000 \\
\hline
\end{tabular}


Table 13: Effects on employment outcomes by job search at baseline

\begin{tabular}{|c|c|c|c|c|c|c|c|c|}
\hline \multirow[b]{2}{*}{ Outcome } & \multicolumn{3}{|c|}{ Transport } & \multicolumn{3}{|c|}{ Job Application Workshop } & \multicolumn{2}{|c|}{ Control Mean } \\
\hline & Low Search Intens. & High Search Intens. & $F(p)$ & Low Search Intens. & High Search Intens. & $F(p)$ & Low Search Intens. & High Search Inte \\
\hline Worked & $\begin{array}{l}0.0420 \\
(.323) \\
{[.797]}\end{array}$ & $\begin{array}{c}0.0370 \\
(.39) \\
{[.797]}\end{array}$ & 0.932 & $\begin{array}{l}0.0590 \\
(.176) \\
{[.459]}\end{array}$ & $\begin{array}{c}-0.0120 \\
(.775) \\
{[.868]}\end{array}$ & 0.243 & 0.554 & 0.569 \\
\hline Hours worked & $\begin{array}{c}-0.777 \\
(.738) \\
{[1]}\end{array}$ & $\begin{array}{l}1.202 \\
(.593) \\
{[.977]}\end{array}$ & 0.565 & $\begin{array}{l}0.610 \\
(.804) \\
{[.868]}\end{array}$ & $\begin{array}{l}-0.185 \\
(.929) \\
{[.868]}\end{array}$ & 0.815 & 26.60 & 25.90 \\
\hline Formal work & $\begin{array}{c}0.0770 \\
(.008)^{* * * *} \\
{[.13]}\end{array}$ & $\begin{array}{l}0.0420 \\
(.127) \\
{[.701]}\end{array}$ & 0.417 & $\begin{array}{c}0.0640 \\
(.028)^{* *} \\
{[.223]}\end{array}$ & $\begin{array}{l}0.0400 \\
(.197) \\
{[.459]}\end{array}$ & 0.605 & 0.203 & 0.241 \\
\hline Perm. work & $\begin{array}{c}0.0440 \\
(.089)^{*} \\
{[.63]}\end{array}$ & $\begin{array}{l}0.0260 \\
(.311) \\
{[.797]}\end{array}$ & 0.647 & $\begin{array}{c}0.0930 \\
(.002)^{* * *} \\
{[.023]^{* *}}\end{array}$ & $\begin{array}{l}0.0390 \\
(.159) \\
{[.459]}\end{array}$ & 0.198 & 0.157 & 0.182 \\
\hline Self-employed & $\begin{array}{c}-0.0100 \\
(.679) \\
{[1]}\end{array}$ & $\begin{array}{c}-0.0360 \\
(.081)^{*} \\
{[.63]}\end{array}$ & 0.397 & $\begin{array}{c}-0.00800 \\
(.747) \\
{[.868]}\end{array}$ & $\begin{array}{c}-0.00300 \\
(.878) \\
{[.868]}\end{array}$ & 0.889 & 0.110 & 0.0827 \\
\hline Monthly earnings & $\begin{array}{l}95.94 \\
(.375) \\
{[.797]}\end{array}$ & $\begin{array}{l}-73.46 \\
(.447) \\
{[.797]}\end{array}$ & 0.234 & $\begin{array}{l}205.1 \\
(.118) \\
{[.459]}\end{array}$ & $\begin{array}{l}-28.94 \\
(.803) \\
{[.868]}\end{array}$ & 0.190 & 1103 & 1181 \\
\hline Satis. with work & $\begin{array}{l}0.0350 \\
(.347) \\
{[.797]}\end{array}$ & $\begin{array}{c}-0.0300 \\
(.416) \\
{[.797]}\end{array}$ & 0.203 & $\begin{array}{l}0.0670 \\
(.067)^{*} \\
{[.369]}\end{array}$ & $\begin{array}{c}-0.0110 \\
(.756) \\
{[.868]}\end{array}$ & 0.117 & 0.229 & 0.243 \\
\hline
\end{tabular}

Note. In this table we report heterogeneous treatment effects for individuals that were searching above and below the median number of weeks in the three months after being surveyed and before the start of the interventions. For each group, we report the intent-to-treat estimates of the direct effects of the transport intervention and the job application workshop on job search outcomes. These are obtained by least squares estimation of equation (2). Below each coefficient estimate, we report a p-value in parenthesis and a q-value in brackets. We correct standard errors to allow for arbitrary correlation at the level of geographical clusters. q-values are obtained using the sharpened procedure of Benjamini et al. (2006). In columns 3 and 6 we report the p-value from F-tests of the null hypotheses that transport subsidies and the job application workshop, respectively, have the same effect for individuals with different levels of education. In the last three columns we report the mean outcome in the control group for the different education categories. ${ }^{* * *} p<0.01,{ }^{* *} p<0.05,{ }^{*} p<0.1$. 
Table 14: Effects on employment outcomes by experience in permanent employment

\begin{tabular}{|c|c|c|c|c|c|c|c|c|}
\hline \multirow[b]{2}{*}{ Outcome } & \multicolumn{3}{|c|}{ Transport } & \multicolumn{3}{|c|}{ Job Application Workshop } & \multicolumn{2}{|c|}{ Control Mean } \\
\hline & Never Perm. Job & Had Perm. Job & $F(p)$ & never Perm. Job & Had Perm. Job & $F(p)$ & Never Perm. Job & Had Perm. Job \\
\hline Worked & $\begin{array}{l}0.0420 \\
(.182) \\
{[.773]}\end{array}$ & $\begin{array}{c}0.0210 \\
(.767) \\
{[1]}\end{array}$ & 0.798 & $\begin{array}{c}0.0230 \\
(.473) \\
{[1]}\end{array}$ & $\begin{array}{c}-0.00300 \\
(.972) \\
{[1]}\end{array}$ & 0.753 & 0.544 & 0.688 \\
\hline Hours worked & $\begin{array}{c}-0.0700 \\
(.966) \\
{[1]}\end{array}$ & $\begin{array}{c}2.879 \\
(.476) \\
{[1]}\end{array}$ & 0.499 & $\begin{array}{c}0.0520 \\
(.975) \\
{[1]}\end{array}$ & $\begin{array}{c}0.803 \\
(.85) \\
{[1]}\end{array}$ & 0.872 & 25.60 & 30.40 \\
\hline Formal work & $\begin{array}{c}0.0660 \\
(.001)^{* * *} \\
{[.017]^{* *}}\end{array}$ & $\begin{array}{c}-0.00500 \\
(.941) \\
{[1]}\end{array}$ & 0.344 & $\begin{array}{c}0.0540 \\
(.008)^{* * *} \\
{[.056]^{*}}\end{array}$ & $\begin{array}{c}0.0210 \\
(.761) \\
{[1]}\end{array}$ & 0.650 & 0.202 & 0.375 \\
\hline Perm. work & $\begin{array}{c}0.0440 \\
(.025)^{* *} \\
{[.194]}\end{array}$ & $\begin{array}{c}-0.0440 \\
(.514) \\
{[1]}\end{array}$ & 0.231 & $\begin{array}{c}0.0690 \\
(0)^{* * * *} \\
{[.005]^{* * *}}\end{array}$ & $\begin{array}{c}0.0170 \\
(.819) \\
{[1]}\end{array}$ & 0.488 & 0.150 & 0.313 \\
\hline Self-employed & $\begin{array}{c}-0.0290 \\
(.093)^{*} \\
{[.597]}\end{array}$ & $\begin{array}{c}0.0230 \\
(.608) \\
{[1]}\end{array}$ & 0.299 & $\begin{array}{c}-0.0120 \\
(.496) \\
{[1]}\end{array}$ & $\begin{array}{c}0.0610 \\
(.223) \\
{[1]}\end{array}$ & 0.190 & 0.0985 & 0.0729 \\
\hline Monthly earnings & $\begin{array}{c}-38.04 \\
(.607) \\
{[1]}\end{array}$ & $\begin{array}{c}391.5 \\
(.13) \\
{[.637]}\end{array}$ & 0.105 & $\begin{array}{c}97.29 \\
(.278) \\
{[1]}\end{array}$ & $\begin{array}{c}-55.85 \\
(.809) \\
{[1]}\end{array}$ & 0.526 & 1074 & 1639 \\
\hline Satis. with work & $\begin{array}{c}0.00100 \\
(.967) \\
{[1]}\end{array}$ & $\begin{array}{c}-0.00200 \\
(.975) \\
{[1]}\end{array}$ & 0.964 & $\begin{array}{c}0.0260 \\
(.354) \\
{[1]}\end{array}$ & $\begin{array}{c}0.0270 \\
(.734) \\
{[1]}\end{array}$ & 0.987 & 0.224 & 0.323 \\
\hline
\end{tabular}

Note. In this table we report heterogenous treatment effects for individuals with and without experience in permanent employment. For each group, we report the intent-to-treat estimates of the direct effects of the transport intervention and the job application workshop on job search outcomes. These are obtained by least squares estimation of equation (2). Below each coefficient estimate, we report a p-value in parenthesis and a q-value in brackets. We correct standard errors to allow for arbitrary correlation at the level of geographical clusters. q-values are obtained using the sharpened procedure of Benjamini et al. (2006). In columns 3 and 6 we report the p-value from F-tests of the null hypotheses that transport subsidies and the job application workshop, respectively, have the same effect for individuals with different levels of education. In the last three columns we report the mean outcome in the control group for the different education categories. ${ }^{* * *} p<0.01,{ }^{* *} p<0.05$, ${ }^{*} \mathrm{p}<0.1$. 
Table 15: Effects on employment outcomes by savings

\begin{tabular}{|c|c|c|c|c|c|c|c|c|}
\hline \multirow[b]{2}{*}{ Outcome } & \multicolumn{3}{|c|}{ Transport } & \multicolumn{3}{|c|}{ Job Application Workshop } & \multicolumn{2}{|c|}{ Control Mean } \\
\hline & Below Med. & Above Med. & $F(p)$ & Below Med. & Above Med. & $F(p)$ & Below Med. & Above Med. \\
\hline Worked & $\begin{array}{c}0.112 \\
(.052)^{*} \\
{[.314]}\end{array}$ & $\begin{array}{l}0.0160 \\
(.599) \\
{[.476]}\end{array}$ & 0.110 & $\begin{array}{c}0.105 \\
(.089)^{*} \\
{[.194]}\end{array}$ & $\begin{array}{c}-0.00900 \\
(.785) \\
{[.75]}\end{array}$ & 0.0942 & 0.554 & 0.565 \\
\hline Hours worked & $\begin{array}{l}5.004 \\
(.101) \\
{[.314]}\end{array}$ & $\begin{array}{l}-1.311 \\
(.413) \\
{[.416]}\end{array}$ & 0.0503 & $\begin{array}{l}4.243 \\
(.182) \\
{[.262]}\end{array}$ & $\begin{array}{c}-1.305 \\
(.43) \\
{[.546]}\end{array}$ & 0.115 & 24.70 & 26.70 \\
\hline Formal work & $\begin{array}{c}0.108 \\
(.005)^{* * *} \\
{[.076]^{*}}\end{array}$ & $\begin{array}{l}0.0430 \\
(.056)^{*} \\
{[.314]}\end{array}$ & 0.154 & $\begin{array}{c}0.0830 \\
(.046)^{* *} \\
{[.15]}\end{array}$ & $\begin{array}{l}0.0390 \\
(.075)^{*} \\
{[.194]}\end{array}$ & 0.353 & 0.251 & 0.214 \\
\hline Perm. work & $\begin{array}{c}0.0600 \\
(.11) \\
{[.314]}\end{array}$ & $\begin{array}{l}0.0270 \\
(.147) \\
{[.346]}\end{array}$ & 0.406 & $\begin{array}{l}0.0490 \\
(.202) \\
{[.262]}\end{array}$ & $\begin{array}{c}0.0680 \\
(.002)^{* * *} \\
{[.023]^{* *}}\end{array}$ & 0.662 & 0.195 & 0.162 \\
\hline Self-employed & $\begin{array}{c}-0.0260 \\
(.502) \\
{[.441]}\end{array}$ & $\begin{array}{c}-0.0230 \\
(.201) \\
{[.346]}\end{array}$ & 0.936 & $\begin{array}{c}-0.00300 \\
(.946) \\
{[.75]}\end{array}$ & $\begin{array}{c}-0.00500 \\
(.802) \\
{[.75]}\end{array}$ & 0.962 & 0.0872 & 0.0980 \\
\hline Monthly earnings & $\begin{array}{c}252.4 \\
(.093)^{*} \\
{[.314]}\end{array}$ & $\begin{array}{l}-71.21 \\
(.406) \\
{[.416]}\end{array}$ & 0.0645 & $\begin{array}{c}318.3 \\
(.028)^{* *} \\
{[.138]}\end{array}$ & $\begin{array}{c}-0.0310 \\
(1) \\
{[.75]}\end{array}$ & 0.0652 & 966 & 1207 \\
\hline Satis. with work & $\begin{array}{l}0.0330 \\
(.524) \\
{[.441]}\end{array}$ & $\begin{array}{c}-0.0100 \\
(.744) \\
{[.544]}\end{array}$ & 0.456 & $\begin{array}{c}0.112 \\
(.024)^{* * *} \\
{[.138]}\end{array}$ & $\begin{array}{c}-0.00400 \\
(.885) \\
{[.75]}\end{array}$ & 0.0370 & 0.205 & 0.248 \\
\hline
\end{tabular}

Note. In this table we report heterogenous treatment effects for individual with baseline savings above and below the median. For each group, we report the intent-to-treat estimates of the direct effects of the transport intervention and the job application workshop on job search outcomes. These are obtained by least squares estimation of equation (2). Below each coefficient estimate, we report a p-value in parenthesis and a q-value in brackets. We correct standard errors to allow for arbitrary correlation at the level of geographical clusters. q-values are obtained using the sharpened procedure of Benjamini et al. (2006). In columns 3 and 6 we report the p-value from F-tests of the null hypotheses that transport subsidies and the job application workshop, respectively, have the same effect for individuals with different levels of education. In the last three columns we report the mean outcome in the control group for the different education categories. ${ }^{* * *} p<0.01,{ }^{* *} p<0.05$, ${ }^{*} \mathrm{p}<0.1$. 
Table 16: Effects on employment outcomes by use of certificates at baseline

\begin{tabular}{|c|c|c|c|c|c|c|c|c|}
\hline \multirow[b]{2}{*}{ Outcome } & \multicolumn{3}{|c|}{ Transport } & \multicolumn{3}{|c|}{ Job Application Workshop } & \multicolumn{2}{|c|}{ Control Mean } \\
\hline & Not used CV/Cert & Used CV/Cert & $F(p)$ & Not used CV/Cert & Used CV/Cert & $F(p)$ & Not used CV/Cert & Used CV/Cert \\
\hline Worked & $\begin{array}{c}0.0350 \\
(.42) \\
{[1]}\end{array}$ & $\begin{array}{c}0.0450 \\
(.216) \\
{[.761]}\end{array}$ & 0.860 & $\begin{array}{c}-0.0300 \\
(.48) \\
{[.725]}\end{array}$ & $\begin{array}{c}0.0740 \\
(.046)^{* *} \\
{[.318]}\end{array}$ & 0.0562 & 0.546 & 0.575 \\
\hline Hours worked & $\begin{array}{c}-0.0410 \\
(.986) \\
{[1]}\end{array}$ & $\begin{array}{c}0.557 \\
(.788) \\
{[1]}\end{array}$ & 0.856 & $\begin{array}{l}-1.882 \\
(.434) \\
{[.725]}\end{array}$ & $\begin{array}{l}2.245 \\
(.249) \\
{[.47]}\end{array}$ & 0.201 & 26.10 & 26.20 \\
\hline Formal work & $\begin{array}{c}0.0690 \\
(.014)^{* *} \\
{[.248]}\end{array}$ & $\begin{array}{l}0.0470 \\
(.109) \\
{[.547]}\end{array}$ & 0.600 & $\begin{array}{l}0.0450 \\
(.093)^{*} \\
{[.318]}\end{array}$ & $\begin{array}{l}0.0520 \\
(.085)^{*} \\
{[.318]}\end{array}$ & 0.856 & 0.128 & 0.301 \\
\hline Perm. work & $\begin{array}{l}0.0440 \\
(.079)^{*} \\
{[.547]}\end{array}$ & $\begin{array}{c}0.0240 \\
(.332) \\
{[1]}\end{array}$ & 0.554 & $\begin{array}{l}0.0490 \\
(.068)^{*} \\
{[.318]}\end{array}$ & $\begin{array}{c}0.0770 \\
(.005)^{* * *} \\
{[.073]^{*}}\end{array}$ & 0.462 & 0.116 & 0.215 \\
\hline Self-employed & $\begin{array}{c}-0.0410 \\
(.086)^{*} \\
{[.547]}\end{array}$ & $\begin{array}{c}-0.00400 \\
(.852) \\
{[1]}\end{array}$ & 0.264 & $\begin{array}{c}-0.0140 \\
(.56) \\
{[.725]}\end{array}$ & $\begin{array}{c}0.00700 \\
(.743) \\
{[.916]}\end{array}$ & 0.519 & 0.125 & 0.0716 \\
\hline Monthly earnings & $\begin{array}{c}22.31 \\
(.839) \\
{[1]}\end{array}$ & $\begin{array}{c}-7.386 \\
(.942) \\
{[1]}\end{array}$ & 0.845 & $\begin{array}{l}92.92 \\
(.472) \\
{[.725]}\end{array}$ & $\begin{array}{l}69.42 \\
(.526) \\
{[.725]}\end{array}$ & 0.889 & 1051 & 1221 \\
\hline Satis. with work & $\begin{array}{c}-0.0140 \\
(.728) \\
{[1]}\end{array}$ & $\begin{array}{c}0.0170 \\
(.633) \\
{[1]}\end{array}$ & 0.555 & $\begin{array}{l}0.0150 \\
(.698) \\
{[.916]}\end{array}$ & $\begin{array}{c}0.0390 \\
(.247) \\
{[.47]}\end{array}$ & 0.632 & 0.255 & 0.222 \\
\hline
\end{tabular}

Note. In this table we report heterogenous treatment effects for individuals who at baseline used certificates or CVs in job applications and individuals that did not use certificates or CVs. For each group, we report the intent-to-treat estimates of the direct effects of the transport intervention and the job application workshop on job search outcomes. These are obtained by least squares estimation of equation (2). Below each coefficient estimate, we report a p-value in parenthesis and a q-value in brackets. We correct standard errors to allow for arbitrary correlation at the level of geographical clusters. q-values are obtained using the sharpened procedure of Benjamini et al. (2006). In columns 3 and 6 we report the p-value from F-tests of the null hypotheses that transport subsidies and the job application workshop, respectively, have the same effect for individuals with different levels of education. In the last three columns we report the mean outcome in the control group for the different education categories. ${ }^{* * *} \mathrm{p}<0.01,{ }^{* *} \mathrm{p}<0.05,{ }^{*} \mathrm{p}<0.1$. 
Table 17: Family indices

\begin{tabular}{|c|c|c|c|c|c|c|c|}
\hline Outcome & Transport & Job App. Workshop & Spillover 1 & Spillover 2 & Control Mean & $\mathrm{F}$ & $\mathrm{N}$ \\
\hline Job Quality & $\begin{array}{c}0.569 \\
(.315) \\
{[1]}\end{array}$ & $\begin{array}{c}0.482 \\
(.448) \\
{[1]}\end{array}$ & $\begin{array}{c}-0.168 \\
(.821) \\
{[1]}\end{array}$ & $\begin{array}{c}0.812 \\
(.456) \\
{[1]}\end{array}$ & -0.218 & 0.889 & 3785 \\
\hline Finan. Outcomes & $\begin{array}{c}0.188 \\
(.436) \\
{[1]}\end{array}$ & $\begin{array}{c}0.153 \\
(.477) \\
{[1]}\end{array}$ & $\begin{array}{c}0.104 \\
(.688) \\
{[1]}\end{array}$ & $\begin{array}{c}-0.00600 \\
(.983) \\
{[1]}\end{array}$ & -0.188 & 0.878 & 3785 \\
\hline Expects and Asps & $\begin{array}{c}-0.0910 \\
(.897) \\
{[1]}\end{array}$ & $\begin{array}{c}0.104 \\
(.86) \\
{[1]}\end{array}$ & $\begin{array}{c}-1.055 \\
(.083)^{*} \\
{[1]}\end{array}$ & $\begin{array}{c}-0.358 \\
(.669) \\
{[1]}\end{array}$ & 0.215 & 0.759 & 2809 \\
\hline Mobility & $\begin{array}{c}0.105 \\
(.865) \\
{[1]}\end{array}$ & $\begin{array}{c}-0.0420 \\
(.951) \\
{[1]}\end{array}$ & $\begin{array}{c}-0.419 \\
(.578) \\
{[1]}\end{array}$ & $\begin{array}{c}-0.801 \\
(.324) \\
{[1]}\end{array}$ & 0.145 & 0.821 & 3779 \\
\hline Education/Skills & $\begin{array}{c}-0.828 \\
(.215) \\
{[1]}\end{array}$ & $\begin{array}{c}-1.175 \\
(.124) \\
{[1]}\end{array}$ & $\begin{array}{c}0.0630 \\
(.936) \\
{[1]}\end{array}$ & $\begin{array}{c}-1.070 \\
(.291) \\
{[1]}\end{array}$ & 0.394 & 0.612 & 3785 \\
\hline Wellbeing & $\begin{array}{c}0.0480 \\
(.772) \\
{[1]}\end{array}$ & $\begin{array}{c}0.185 \\
(.234) \\
{[1]}\end{array}$ & $\begin{array}{c}0.0250 \\
(.888) \\
{[1]}\end{array}$ & $\begin{array}{c}0.106 \\
(.637) \\
{[1]}\end{array}$ & -0.0640 & 0.430 & 3781 \\
\hline Networks & $\begin{array}{c}-0.301 \\
(.375) \\
{[1]}\end{array}$ & $\begin{array}{c}-0.353 \\
(.332) \\
{[1]}\end{array}$ & $\begin{array}{c}-0.493 \\
(.198) \\
{[1]}\end{array}$ & $\begin{array}{c}-0.228 \\
(.604) \\
{[1]}\end{array}$ & 0.111 & 0.883 & 3761 \\
\hline
\end{tabular}

Note. In this table we report the intent-to-treat estimates of the direct and indirect effects of the transport intervention and the job application workshop on the summary indices for different families of outcomes. These are obtained by least squares estimation of equation (1), weighting each observation by the inverse of the probability of being sampled. Below each coefficient estimate, we report a p-value in parenthesis and a q-value in brackets. We correct standard errors to allow for arbitrary correlation at the level of geographical clusters. q-values are obtained using the sharpened procedure of Benjamini et al. (2006). In the last three columns we report the mean outcome for the control group, the p-value from a F-test of the null hypothesis that transport subsidies and the job application workshop have the same effect, and the number of observations. ${ }^{* * *} \mathrm{p}<0.01,{ }^{* *} \mathrm{p}<0.05,{ }^{*} \mathrm{p}<0.1$. 
Table 18: Other job quality measures

\begin{tabular}{|c|c|c|c|c|c|c|c|}
\hline Outcome & Transport & Job App. Workshop & Spillover 1 & Spillover 2 & Control Mean & $\mathrm{F}$ & $\mathrm{N}$ \\
\hline Received job by interview & $\begin{array}{c}0.0410 \\
(.009)^{* * * *} \\
{[.046]^{* *}}\end{array}$ & $\begin{array}{l}0.0440 \\
(.015)^{* *} \\
{[.083]^{*}}\end{array}$ & $\begin{array}{c}0.0250 \\
(.235) \\
{[1]}\end{array}$ & $\begin{array}{c}0.0710 \\
(.024)^{* *} \\
{[.137]}\end{array}$ & 0.167 & 0.860 & 3785 \\
\hline Office work (7d) & $\begin{array}{c}0.0260 \\
(.287) \\
{[.62]}\end{array}$ & $\begin{array}{c}0.00200 \\
(.93) \\
{[1]}\end{array}$ & $\begin{array}{c}-0.0180 \\
(.498) \\
{[1]}\end{array}$ & $\begin{array}{c}0.00600 \\
(.867) \\
{[1]}\end{array}$ & 0.201 & 0.305 & 3785 \\
\hline Skills match with tasks & $\begin{array}{c}0.00900 \\
(.76) \\
{[.916]}\end{array}$ & $\begin{array}{c}0.00500 \\
(.861) \\
{[1]}\end{array}$ & $\begin{array}{c}0.0310 \\
(.372) \\
{[1]}\end{array}$ & $\begin{array}{c}0 \\
(.998) \\
{[1]}\end{array}$ & 0.130 & 0.886 & 3785 \\
\hline Overqualified & $\begin{array}{c}0.0380 \\
(.279) \\
{[.62]}\end{array}$ & $\begin{array}{c}0.0300 \\
(.384) \\
{[1]}\end{array}$ & $\begin{array}{c}-0.0380 \\
(.304) \\
{[1]}\end{array}$ & $\begin{array}{c}0.0620 \\
(.22) \\
{[.783]}\end{array}$ & 0.291 & 0.797 & 3785 \\
\hline Underqualified & $\begin{array}{c}-0.0160 \\
(.397) \\
{[.659]}\end{array}$ & $\begin{array}{c}-0.0120 \\
(.547) \\
{[1]}\end{array}$ & $\begin{array}{c}-0.0130 \\
(.565) \\
{[1]}\end{array}$ & $\begin{array}{c}-0.0200 \\
(.429) \\
{[1]}\end{array}$ & 0.0820 & 0.781 & 3785 \\
\hline
\end{tabular}

Note. In this table we report the intent-to-treat estimates of the direct and indirect effects of the transport intervention and the job application workshop on secondary employment outcomes. These are obtained by least squares estimation of equation (1), weighting each observation by the inverse of the probability of being sampled. Below each coefficient estimate, we report a p-value in parenthesis and a q-value in brackets. We correct standard errors to allow for arbitrary correlation at the level of geographical clusters. q-values are obtained using the sharpened procedure of Benjamini et al. (2006). In the last three columns we report the mean outcome for the control group, the p-value from a F-test of the null hypothesis that transport subsidies and the job application workshop have the same effect, and the number of observations. ${ }^{* * *} \mathrm{p}<0.01,{ }^{* *} \mathrm{p}<0.05$, * $\mathrm{p}<0.1$. 
Table 19: Financial outcomes

\begin{tabular}{lccccccc}
\hline Outcome & Transport & Job App. Workshop & Spillover 1 & Spillover 2 & Control Mean & $\mathrm{F}$ & $\mathrm{N}$ \\
\hline \multirow{2}{*}{ Expenditure (7d) } & 26.52 & 18.00 & -7.040 & -60.53 & 506.4 & 0.833 & 3785 \\
& $(.502)$ & $(.643)$ & $(.859)$ & $(.145)$ & & & \\
& {$[1]$} & {$[1]$} & {$[1]$} & {$[.768]$} & & & \\
Savings (total) & 513.6 & -772.0 & -468.5 & 100.5 & 6907 & 0.616 & 1692 \\
& $(.849)$ & $(.566)$ & $(.746)$ & $(.951)$ & & & \\
& {$[1]$} & {$[1]$} & {$[1]$} & {$[1]$} & & & \\
& & & & & & & \\
& 0.490 & 0.240 & 0.467 & 0.527 & -0.404 & 0.636 & 3785 \\
& $(.376)$ & $(.627)$ & $(.466)$ & $(.503)$ & & &
\end{tabular}

Note. In this table we report the intent-to-treat estimates of the direct and indirect effects of the transport intervention and the job application workshop on financial outcomes. These are obtained by least squares estimation of equation (1), weighting each observation by the inverse of the probability of being sampled. Below each coefficient estimate, we report a p-value in parenthesis and a q-value in brackets. We correct standard errors to allow for arbitrary correlation at the level of geographical clusters. q-values are obtained using the sharpened procedure of Benjamini et al. (2006). In the last three columns we report the mean outcome for the control group, the p-value from a F-test of the null hypothesis that transport subsidies and the job application workshop have the same effect, and the number of observations. ${ }^{* * *} \mathrm{p}<0.01,{ }^{* *} \mathrm{p}<0.05,{ }^{*} \mathrm{p}<0.1$.

Table 20: Expectations, aspirations, reservation wages

\begin{tabular}{|c|c|c|c|c|c|c|c|}
\hline Outcome & Transport & Job App. Workshop & Spillover 1 & Spillover 2 & Control Mean & $\mathrm{F}$ & $\mathrm{N}$ \\
\hline Offers expected (next $4 \mathrm{~m}$ ) & $\begin{array}{c}-0.00700 \\
(.962) \\
{[1]}\end{array}$ & $\begin{array}{c}0.268 \\
(.079)^{*} \\
{[.366]}\end{array}$ & $\begin{array}{l}-0.165 \\
(.263) \\
{[.652]}\end{array}$ & $\begin{array}{c}-0.194 \\
(.16) \\
{[.333]}\end{array}$ & 1.421 & 0.0804 & 3521 \\
\hline Reservation wage & $\begin{array}{c}3.910 \\
(.962) \\
{[1]}\end{array}$ & $\begin{array}{l}-93.73 \\
(.201) \\
{[.366]}\end{array}$ & $\begin{array}{c}-12.69 \\
(.887) \\
{[1]}\end{array}$ & $\begin{array}{c}143.6 \\
(.19) \\
{[.333]}\end{array}$ & 2023 & 0.277 & 3319 \\
\hline Aspiration wage (in 5y) & $\begin{array}{c}624.7 \\
(.37) \\
{[1]}\end{array}$ & $\begin{array}{l}673.2 \\
(.404) \\
{[.366]}\end{array}$ & $\begin{array}{c}438.8 \\
(.517) \\
{[1]}\end{array}$ & $\begin{array}{l}981.2 \\
(.206) \\
{[.333]}\end{array}$ & 7097 & 0.957 & 3446 \\
\hline Weeks expected to be without permanent job & $\begin{array}{c}2.044 \\
(.636) \\
{[1]}\end{array}$ & $\begin{array}{l}-4.518 \\
(.179) \\
{[.366]}\end{array}$ & $\begin{array}{c}-9.528 \\
(.003)^{* * *} \\
{[.011]^{* *}}\end{array}$ & $\begin{array}{l}-5.373 \\
(.249) \\
{[.333]}\end{array}$ & 30.23 & 0.0883 & 1809 \\
\hline
\end{tabular}

Note. In this table we report the intent-to-treat estimates of the direct and indirect effects of the transport intervention and the job application workshop on expectations, aspirations and reservation wages. These are obtained by least squares estimation of equation (1), weighting each observation by the inverse of the probability of being sampled. Below each coefficient estimate, we report a p-value in parenthesis and a q-value in brackets. We correct standard errors to allow for arbitrary correlation at the level of geographical clusters. q-values are obtained using the sharpened procedure of Benjamini et al. (2006). In the last three columns we report the mean outcome for the control group, the p-value from a F-test of the null hypothesis that transport subsidies and the job application workshop have the same effect, and the number of observations. *** $\mathrm{p}<0.01,{ }^{* *} \mathrm{p}<0.05,{ }^{*} \mathrm{p}<0.1$. 
Table 21: Mobility

\begin{tabular}{|c|c|c|c|c|c|c|c|}
\hline Outcome & Transport & Job App. Workshop & Spillover 1 & Spillover 2 & Control Mean & $\mathrm{F}$ & $\mathrm{N}$ \\
\hline Trip to center $(7 \mathrm{~d})$ & $\begin{array}{c}0.134 \\
(.435) \\
{[1]}\end{array}$ & $\begin{array}{c}-0.0410 \\
(.821) \\
{[.677]}\end{array}$ & $\begin{array}{c}-0.136 \\
(.444) \\
{[1]}\end{array}$ & $\begin{array}{c}-0.264 \\
(.252) \\
{[1]}\end{array}$ & 2.372 & 0.340 & 3347 \\
\hline Works away from home & $\begin{array}{c}-0.0330 \\
(.211) \\
{[1]}\end{array}$ & $\begin{array}{c}-0.0370 \\
(.167) \\
{[.638]}\end{array}$ & $\begin{array}{c}-0.0390 \\
(.166) \\
{[1]}\end{array}$ & $\begin{array}{c}-0.0430 \\
(.267) \\
{[1]}\end{array}$ & 0.851 & 0.891 & 3785 \\
\hline Moved within Addis & $\begin{array}{c}-0.00200 \\
(.914) \\
{[1]}\end{array}$ & $\begin{array}{l}0.0240 \\
(.242) \\
{[.638]}\end{array}$ & $\begin{array}{c}0.00600 \\
(.792) \\
{[1]}\end{array}$ & $\begin{array}{c}0.00800 \\
(.767) \\
{[1]}\end{array}$ & 0.0820 & 0.192 & 3785 \\
\hline
\end{tabular}

Note. In this table we report the intent-to-treat estimates of the direct and indirect effects of the transport intervention and the job application workshop on outcomes related to mobility. These are obtained by least squares estimation of equation (1), weighting each observation by the inverse of the probability of being sampled. Below each coefficient estimate, we report a p-value in parenthesis and a q-value in brackets. We correct standard errors to allow for arbitrary correlation at the level of geographical clusters. q-values are obtained using the sharpened procedure of Benjamini et al. (2006). In the last three columns we report the mean outcome for the control group, the p-value from a F-test of the null hypothesis that transport subsidies and the job application workshop have the same effect, and the number of observations. ${ }^{* * *} \mathrm{p}<0.01,{ }^{* *} \mathrm{p}<0.05$, * $\mathrm{p}<0.1$. 
Table 22: Education and training

\begin{tabular}{|c|c|c|c|c|c|c|c|}
\hline Outcome & Transport & Job App. Workshop & Spillover 1 & Spillover 2 & Control Mean & $\mathrm{F}$ & $\mathrm{N}$ \\
\hline In full-time education & $\begin{array}{c}-0.00700 \\
(.363) \\
{[.694]}\end{array}$ & $\begin{array}{c}0 \\
(.975) \\
{[1]}\end{array}$ & $\begin{array}{c}0.00300 \\
(.803) \\
{[1]}\end{array}$ & $\begin{array}{c}0.0330 \\
(.131) \\
{[.212]}\end{array}$ & 0.0210 & 0.379 & 3785 \\
\hline In part-time education & $\begin{array}{c}-0.0480 \\
(.016)^{* *} \\
{[.108]}\end{array}$ & $\begin{array}{c}-0.0330 \\
(.139) \\
{[.61]}\end{array}$ & $\begin{array}{c}-0.0130 \\
(.619) \\
{[1]}\end{array}$ & $\begin{array}{c}-0.0210 \\
(.508) \\
{[.439]}\end{array}$ & 0.142 & 0.431 & 3785 \\
\hline In informal training & $\begin{array}{c}-0.0100 \\
(.512) \\
{[.694]}\end{array}$ & $\begin{array}{c}-0.0100 \\
(.498) \\
{[.739]}\end{array}$ & $\begin{array}{c}-0.00700 \\
(.655) \\
{[1]}\end{array}$ & $\begin{array}{l}-0.0410 \\
(.001)^{* * *} \\
{[.009]^{* * *}}\end{array}$ & 0.0380 & 0.995 & 3785 \\
\hline Graduated (in past $12 \mathrm{~m}$ ) & $\begin{array}{c}0.0110 \\
(.5) \\
{[.694]}\end{array}$ & $\begin{array}{c}-0.0130 \\
(.436) \\
{[.739]}\end{array}$ & $\begin{array}{c}0.0160 \\
(.434) \\
{[1]}\end{array}$ & $\begin{array}{c}-0.0190 \\
(.392) \\
{[.416]}\end{array}$ & 0.0850 & 0.138 & 3785 \\
\hline Graduated from vocational degree (in past $12 \mathrm{~m}$ ) & $\begin{array}{l}0.0160 \\
(.134) \\
{[.504]}\end{array}$ & $\begin{array}{c}0.00600 \\
(.531) \\
{[.739]}\end{array}$ & $\begin{array}{c}0.00500 \\
(.644) \\
{[1]}\end{array}$ & $\begin{array}{c}0.00200 \\
(.893) \\
{[.807]}\end{array}$ & 0.0220 & 0.372 & 3785 \\
\hline Graduated from training (in past $12 \mathrm{~m}$ ) & $\begin{array}{c}-0.00100 \\
(.931) \\
{[1]}\end{array}$ & $\begin{array}{c}-0.0220 \\
(.063)^{*} \\
{[.61]}\end{array}$ & $\begin{array}{c}0.0190 \\
(.238) \\
{[1]}\end{array}$ & $\begin{array}{l}-0.0280 \\
(.024)^{* *} \\
{[.064]^{*}}\end{array}$ & 0.0480 & 0.0952 & 3785 \\
\hline
\end{tabular}

Note. In this table we report the intent-to-treat estimates of the direct and indirect effects of the transport intervention and the job application workshop on education and training. These are obtained by least squares estimation of equation (1), weighting each observation by the inverse of the probability of being sampled. Below each coefficient estimate, we report a p-value in parenthesis and a q-value in brackets. We correct standard errors to allow for arbitrary correlation at the level of geographical clusters. q-values are obtained using the sharpened procedure of Benjamini et al. (2006). In the last three columns we report the mean outcome for the control group, the p-value from a F-test of the null hypothesis that transport subsidies and the job application workshop have the same effect, and the number of observations. ${ }^{* * *} \mathrm{p}<0.01,{ }^{* *} \mathrm{p}<0.05$, * $\mathrm{p}<0.1$. 
Table 23: Psychological outcomes

\begin{tabular}{|c|c|c|c|c|c|c|c|}
\hline Outcome & Transport & Job App. Workshop & Spillover 1 & Spillover 2 & Control Mean & $\mathrm{F}$ & $\mathrm{N}$ \\
\hline Life satisfaction $(0-10)$ & $\begin{array}{c}0.166 \\
(.207) \\
{[1]}\end{array}$ & $\begin{array}{c}0.155 \\
(.248) \\
{[1]}\end{array}$ & $\begin{array}{c}0.199 \\
(.19) \\
{[1]}\end{array}$ & $\begin{array}{c}0.330 \\
(.143) \\
{[1]}\end{array}$ & 4.798 & 0.934 & 3351 \\
\hline Locus of control (0-10) & $\begin{array}{c}0.0200 \\
(.946) \\
{[1]}\end{array}$ & $\begin{array}{c}-0.0280 \\
(.922) \\
{[1]}\end{array}$ & $\begin{array}{c}-0.152 \\
(.648) \\
{[1]}\end{array}$ & $\begin{array}{c}0.00200 \\
(.994) \\
{[1]}\end{array}$ & 6.207 & 0.871 & 3353 \\
\hline Oneness with society & $\begin{array}{c}-0.0310 \\
(.827) \\
{[1]}\end{array}$ & $\begin{array}{c}0.0480 \\
(.731) \\
{[1]}\end{array}$ & $\begin{array}{c}-0.0210 \\
(.887) \\
{[1]}\end{array}$ & $\begin{array}{c}0.118 \\
(.526) \\
{[1]}\end{array}$ & 4.738 & 0.547 & 3353 \\
\hline Trust in other people (1-4) & $\begin{array}{c}0.0780 \\
(.338) \\
{[1]}\end{array}$ & $\begin{array}{c}0.0470 \\
(.608) \\
{[1]}\end{array}$ & $\begin{array}{c}0.0260 \\
(.767) \\
{[1]}\end{array}$ & $\begin{array}{c}-0.0250 \\
(.81) \\
{[1]}\end{array}$ & 2.027 & 0.725 & 3352 \\
\hline
\end{tabular}

Note. In this table we report the intent-to-treat estimates of the direct and indirect effects of the transport intervention and the job application workshop on psychological outcomes. These are obtained by least squares estimation of equation (1), weighting each observation by the inverse of the probability of being sampled. Below each coefficient estimate, we report a p-value in parenthesis and a q-value in brackets. We correct standard errors to allow for arbitrary correlation at the level of geographical clusters. q-values are obtained using the sharpened procedure of Benjamini et al. (2006). In the last three columns we report the mean outcome for the control group, the p-value from a F-test of the null hypothesis that transport subsidies and the job application workshop have the same effect, and the number of observations. ${ }^{* * *} \mathrm{p}<0.01,{ }^{* *} \mathrm{p}<0.05,{ }^{*}$ $\mathrm{p}<0.1$.

Table 24: Social networks

\begin{tabular}{|c|c|c|c|c|c|c|c|}
\hline Outcome & Transport & Job App. Workshop & Spillover 1 & Spillover 2 & Control Mean & $\mathrm{F}$ & $\mathrm{N}$ \\
\hline $\begin{array}{l}\text { Number of people with who regularly } \\
\text { shares information about job opportunities }\end{array}$ & $\begin{array}{c}-0.378 \\
(.335) \\
{[1]}\end{array}$ & $\begin{array}{c}-0.592 \\
(.115) \\
{[.85]}\end{array}$ & $\begin{array}{l}-0.641 \\
(.106) \\
{[.741]}\end{array}$ & $\begin{array}{c}-0.454 \\
(.346) \\
{[.975]}\end{array}$ & 5.242 & 0.558 & 3748 \\
\hline Number of people with permanent jobs in job network & $\begin{array}{c}0.120 \\
(.57) \\
{[1]}\end{array}$ & $\begin{array}{l}0.118 \\
(.618) \\
{[.859]}\end{array}$ & $\begin{array}{c}-0.0630 \\
(.799) \\
{[1]}\end{array}$ & $\begin{array}{l}0.384 \\
(.208) \\
{[.975]}\end{array}$ & 2.440 & 0.991 & 3383 \\
\hline Can access guarantor for job (in next month) & $\begin{array}{c}-0.00300 \\
(.955) \\
{[1]}\end{array}$ & $\begin{array}{c}-0.0640 \\
(.231) \\
{[.85]}\end{array}$ & $\begin{array}{c}-0.0240 \\
(.69) \\
{[1]}\end{array}$ & $\begin{array}{c}-0.00200 \\
(.974) \\
{[.975]}\end{array}$ & 1.220 & 0.232 & 3350 \\
\hline $\begin{array}{l}\text { Number of meetings of voluntary associations } \\
\text { attended (past 30d) }\end{array}$ & $\begin{array}{c}0.00800 \\
(.892) \\
{[1]}\end{array}$ & $\begin{array}{c}0.00700 \\
(.913) \\
{[.859]}\end{array}$ & $\begin{array}{c}-0.0330 \\
(.635) \\
{[1]}\end{array}$ & $\begin{array}{c}-0.0550 \\
(.37) \\
{[.975]}\end{array}$ & 0.0970 & 0.977 & 3785 \\
\hline
\end{tabular}

Note. In this table we report the intent-to-treat estimates of the direct and indirect effects of the transport intervention and the job application workshop on social networks. These are obtained by least squares estimation of equation (1), weighting each observation by the inverse of the probability of being sampled. Below each coefficient estimate, we report a p-value in parenthesis and a q-value in brackets. We correct standard errors to allow for arbitrary correlation at the level of geographical clusters. q-values are obtained using the sharpened procedure of Benjamini et al. (2006). In the last three columns we report the mean outcome for the control group, the p-value from a F-test of the null hypothesis that transport subsidies and the job application workshop have the same effect, and the number of observations. ${ }^{* * *} \mathrm{p}<0.01,{ }^{* *} \mathrm{p}<0.05,{ }^{*} \mathrm{p}<0.1$. 
Table 25: Lee bounds

\begin{tabular}{|c|c|c|c|}
\hline & & Transport & Workshop \\
\hline \multirow[t]{2}{*}{ Permanent work } & Upper bound & $\begin{array}{c}0.032 \\
(0.076)^{*}\end{array}$ & $\begin{array}{c}0.068 \\
(0.000)^{* * *}\end{array}$ \\
\hline & Lower bound & $\begin{array}{c}0.021 \\
(0.339)\end{array}$ & $\begin{array}{c}0.043 \\
(0.047)^{* *}\end{array}$ \\
\hline \multirow[t]{2}{*}{ Written agreement } & Upper bound & $\begin{array}{c}0.061 \\
(0.004)^{* * *}\end{array}$ & $\begin{array}{c}0.061 \\
(0.004)^{* * *}\end{array}$ \\
\hline & Lower bound & $\begin{array}{c}0.050 \\
(0.035)^{* *}\end{array}$ & $\begin{array}{c}0.036 \\
(0.130)\end{array}$ \\
\hline
\end{tabular}

Note. In this table we report the Lee bounds for the estimates of effects of the transport intervention and the job application workshop on permanent work and written agreement. ${ }^{* * *} \mathrm{p}<0.01,{ }^{* *} \mathrm{p}<0.05,{ }^{*} \mathrm{p}<0.1$.

Table 26: Predicted skills and employment outcomes: all workers

\begin{tabular}{|c|c|c|c|c|}
\hline & $\begin{array}{c}\text { Work } \\
(1)\end{array}$ & $\begin{array}{l}\text { Permanent work } \\
\text { (2) }\end{array}$ & $\begin{array}{c}\text { Written agreement } \\
\text { (3) }\end{array}$ & $\begin{array}{c}\text { Earnings } \\
(4)\end{array}$ \\
\hline Predicted score & $\begin{array}{c}.053 \\
(.022)^{* *}\end{array}$ & $\begin{array}{c}.047 \\
(.017)^{* * *}\end{array}$ & $\begin{array}{c}.063 \\
(.019)^{* * *}\end{array}$ & $\begin{array}{c}352.393 \\
(102.618)^{* * *}\end{array}$ \\
\hline Workshop & $\begin{array}{l}.036 \\
. .029)\end{array}$ & $\begin{array}{l}.034 \\
(.021)\end{array}$ & $\begin{array}{l}.041 \\
(.022)^{*}\end{array}$ & $\begin{array}{c}56.538 \\
(115.825)\end{array}$ \\
\hline Predicted score ${ }^{*}$ workshop & $\begin{array}{l}-.022 \\
(.029)\end{array}$ & $\begin{array}{l}-.018 \\
(.023)\end{array}$ & $\begin{array}{l}-.044 \\
(.028)\end{array}$ & $\begin{array}{l}-35.074 \\
(141.522)\end{array}$ \\
\hline Const. & $\begin{array}{l}.560 \\
(.022)^{* * *}\end{array}$ & $(.016)^{* * *}$ & $(.014)^{* * *}$ & $\begin{array}{l}1132.593 \\
(87.763)^{* * *}\end{array}$ \\
\hline Obs. & 1463 & 1463 & 1463 & 1448 \\
\hline
\end{tabular}

Note. In each column we report the results of an ordinary least squares regression of the outcome in the column heading on predicted grades, a dummy for being invited to the job workshop and the interaction of these two variables. In parentheses, we report standard errors obtained through a bootstrapping procedure for generated regressors. The sample includes all individuals in the control group and in the job application group. ${ }^{* * *} \mathrm{p}<0.01,{ }^{* *} \mathrm{p}<0.05,{ }^{*} \mathrm{p}<0.1$.

Table 27: Predicted skills and employment outcomes: workers with at most secondary education

\begin{tabular}{|c|c|c|c|c|}
\hline & $\begin{array}{c}\text { Work } \\
(1)\end{array}$ & $\begin{array}{c}\text { Permanent work } \\
(2)\end{array}$ & $\frac{\text { Written agreement }}{\text { (3) }}$ & $\begin{array}{c}\text { Earnings } \\
(4)\end{array}$ \\
\hline Predicted score & $\begin{array}{l}-.042 \\
(.057)\end{array}$ & $\begin{array}{l}-.039 \\
(.030)\end{array}$ & $\begin{array}{l}-.0004 \\
(.036)\end{array}$ & $\begin{array}{l}-134.476 \\
(202.789)\end{array}$ \\
\hline Workshop & $\begin{array}{l}.016 \\
.062)\end{array}$ & $\begin{array}{c}.155 \\
(.038)^{* * *}\end{array}$ & $\begin{array}{l}.056 \\
.039)\end{array}$ & $\begin{array}{l}202.050 \\
(178.431)\end{array}$ \\
\hline Predicted score * workshop & $\begin{array}{l}.035 \\
.077)\end{array}$ & $\begin{array}{l}.091 \\
(.053)^{*}\end{array}$ & $\begin{array}{l}-.021 \\
(.057)\end{array}$ & $\begin{array}{l}253.776 \\
(334.006)\end{array}$ \\
\hline Const. & $(.042)^{* * *}$ & $(.018)^{* *}$ & $\begin{array}{c}.109 \\
(.025)^{* * *}\end{array}$ & $\begin{array}{r}687.601 \\
(114.227)^{* * *}\end{array}$ \\
\hline Obs. & 452 & 452 & 452 & 448 \\
\hline
\end{tabular}

$\overline{\text { Note. In each column we report the results of an ordinary least squares regression of the outcome in the column heading on }}$ predicted grades, a dummy for being invited to the job workshop and the interaction of these two variables. In parentheses, we report standard errors obtained through a bootstrapping procedure for generated regressors. The sample includes all individuals with at most a high school degree in the control group and in the job application group. ${ }^{* * *} \mathrm{p}<0.01,{ }^{* *} \mathrm{p}<0.05$, ${ }^{*} \mathrm{p}<0.1$. 